\title{
Understanding Psychological Aspects of Chronic Pain in Interventional Pain Management
}

\author{
Laxmaiah Manchikanti, MD*, Bert Fellows, MA*, and Vijay Singh, MD**
}

There is no doubt that chronic pain is recognized as a biopsychosocial phenomenon in which biological, psychological, and social factors dynamically interact with each other. Thus, the role of psychological factors and understanding chronic, persistent disabling pain has been well recognized, but poorly understood. Approximately $1 / 2$ to $2 / 3$ of all patients diagnosed with chronic pain manifest to various levels of psychological distress.

Chronic pain and psychological disorders are the two most common elements in the United States. Statistics show that, approximately $22 \%$ of Americans suffer from a diagnosable mental disorder in a given year. In addition, $28 \%$ of the American population suffers with chronic pain. Depression in chronic pain is the most common condition, followed by generalized anxiety disorder, somatization disorder, and drug dependence. However, psychogenic pain appears to be the least prevalent of all psychopathological issues.

Chronic pain disability is a complex psychosocial economic phenomenon. There is no data in the literature with regards to treatment of personality disorders, anxiety disorders, and somatization disorders in managing chronic pain. In contrast, treatment of depression and the influence of treatment on outcomes have been studied to some extent.

In conclusion, patients with chronic pain frequently have psychopathology - most often common depressive disorders, anxiety disorders, somatization disorders, drug dependence and occasionally personality disorders. This review discusses various issues involved with psychopathology in chronic pain including epidemiology; relationship of psychopathology to pain; influence of depression, generalized anxiety disorder, somatization, and personality disorders on chronic pain, along with diagnosis and management in interventional pain management.

Keywords: Chronic pain, Psychophysiology, psychopathology, biopsychosocial approach, depression, generalized anxiety disorder, somatization disorder
Chronic pain is recognized as a multidimensional problem with both sensory and affective components, and is viewed as a biopsychosocial phenomenon in which biological, psychological and social factors dynamically interact with each other (1-3). Thus, the role of psychological factors in understanding chronic, persistent disabling pain has been well recognized. The fact that chronic pain patients present with a wide range of associated emotions is not only well known, but overemphasized (3-14). Approximately one half to two thirds of all patients diagnosed with chronic pain manifest various levels of psychosocial distress. A significant proportion of patients with chronic

From Pain Management Center of Paducah, Paducah, Kentucky and Pain Diagnostic Associates, Niagara, Wisconsin. *Medical director and" psychologist at Pain Management Center of Paducah. **Medical director of Pain Diagnostic Associates. Address Correspondence: Laxmaiah Manchkianti, MD, 2831 Lone Oak Road, Paducah, KY 42003. E-mail: drm@asipp.org pain are diagnosed with reactive disorders, including depression, anxiety, somatization, personality disorders and various nonspecific issues, such as emotion, anger, and loss of self-esteem (3-14). However, the high rates of reactive disorders in patients with chronic pain, even though well recognized, are very poorly understood. Any discussion of psychiatric disorders in patients with chronic pain is haunted by the concept of psychogenic pain (2). Continued exploration of the psychological factors in chronic pain, with an inordinate interest in this subject, have resulted in an explosion of literature. Psychological abnormalities, their diagnosis and management is an integral part of interventional pain management.

Thus, psychological issues are not only challenging for an interventional pain practitioner, but also mandate that provider develop insight into these issues. Psychological issues may influence significantly the diagnosis, prognosis and outcomes. 


\section{HISTORICAL CONCEPTS}

The association between the mind and the body is well recognized and accepted, wheras the relationship between chronic pain and psychopathology continues to be controversial among physicians, philosophers, physiologists, and psychologists. Hippocrates (400-300 BC), proposed one of the earliest temperamental theories of personality defining four bodily fluids (humors) as responsible for specific personality or temperament types, as well as for various physical or mental illnesses, and was elaborated on by Galen (AD 130-200) (9).

With the advent of physical medicine during the Renaissance, the historical view of the interaction between mind and body started losing favor in the $17^{\text {th }}$ century. During the Renaissance period, the perspective that the mind (or the soul) influenced the body began to be regarded as unscientific and many of the influential works during this period marked the advancement of the view that the body can be explained by its own mechanisms (9).

The emergence of behavioral medicine and health psychology in the 1960s, and the purported understanding of interaction between psychological and physiological factors led to further exploration of mind/body relationships, leading to the development of the biopsychosocial approach to medicine in the 1980s and 1990s (15-21). The biopsychosocial approach has dominated chronic pain management, at least among academicians, with efforts to introduce "psychosocial" approaches. In addition, continued apparent claims of proper understanding of pain continue to remain on the biopsychosocial model of pain. However, multidimensional mechanisms and multidisciplinary management have taken on different meanings for different specialties, ignoring the fundamental facts that pain is not explained on pure theories of either physical or psychological basis. During the same time, behavioral etiology and dubious management also have been introduced. In fact, pain management, in some circles, has reached a stage of psychosocial reductionistic approach, which has essentially eliminated the bio part from the biopsychosocial approach, leaving "psychosocial" "psychological" or "functional approaches."

\section{EPIDEMIOLOGY}

Chronic pain and psychological disorders are the two most common ailments in the United States. An estimated 22\% of Americans, or one in five adults, suffer from a diagnosable mental disorder in a given year $(22,23)$. Approxi- mately $28 \%$ of the population suffers with chronic pain. Chronic pain and psychological disorders, with their associated disability, are major socio-economic problems (24, $25)$. Thus, the issue of the association between chronic pain and psychological disorders is crucial in interventional pain practices. In addition to chronic pain of physical origin associated with psychological issues, there is also an explosive and unproven issue of psychogenic pain (26).

Depression in chronic pain is the most common condition, followed by generalized anxiety disorder, somatization disorder, and drug dependence. Psychogenic pain appears to be the least prevalent of all psychopathological issues (26). It has been shown that approximately $10 \%$ of the US population, present with a depressive disorder, about $13 \%$ of the population suffer with an anxiety disorder, which co-occurs frequently with depressive disorders and substance abuse disorders (22-18). Multiple authors (3-14, 30-39) have shown higher prevalence of depressive and anxiety disorders associated with chronic pain.

Compared to depression and anxiety, somatization disorder is a complex and confusing psychiatric diagnosis often alleged to have been associated with chronic pain. Aronoff et al (40) questioned the validity of pain disorder and somatization disorder as diagnostic entities. The prevalence of somatization disorder in the community has been reported to be $0.13 \%$ and $0.4 \%$, with the vast majority of cases being women (2). Fink et al (41) showed that approximately $22 \%$ to $58 \%$ of the patients in primary care fulfill the diagnostic criteria for a somatoform disorder, which is similar to the prevalence of mental disorders in primary care patients, described as $14 \%$ and $36 \%(42,43)$. Fishbain (44) described that the term somatization has become extremely common in the medical literature. However, there is little agreement about its definition. It was also stated that somatization does not represent a specific psychiatric or medical diagnosis and does not necessarily imply that a psychiatric disorder must be present (45). Thus, somatization is a diagnostic entity in approximately $60 \%$ to $80 \%$ of physically healthy people experiencing somatic symptoms in any given week (46). However, somatization can be, and most frequently is, associated with physical diseases, specifically chronic pain $(47,48)$. Its prevalence and influence on chronic pain are controversial, but has been shown to be significantly higher than normal population in well conducted studies $(37,49)$.

Similar to the reactive disorders, the influence of personality on chronic pain has been described extensively. Even 
though there is no causal relationship between personality disorders and chronic pain, many of the early theories of chronic pain maintain that personality plays an important role in the development and maintenance of chronic pain conditions (50-55). A multitude of studies have shown the existence of personality disorders in patients with chronic pain. However, no single personality disorder has been proven to be associated with chronic pain. Thus, the evidence so far is not only confusing, but grossly inconclusive (37-39).

\section{PSYCHOPATHOLOGY AND PAIN}

It is a common myth that psychological factors lead to chronic pain. While this may not be true, it is commonly presumed that psychological factors play an important role in the natural history of chronic pain. Correlation of psychological status with work absence, claims for financial compensation, response to treatment, progression of acute pain to chronic pain and disability has been claimed (35, 56-64). However, the literature is also replete with descriptions of the influence of psychosocial factors such as job satisfaction, back pain and work absence (56, 65-70). Dersh et al (3) described that unrecognized and untreated psychopathology can significantly interfere with successful rehabilitation. Gatchel (71) characterized rehabilitation programs without a psychological component as "doomed to failure." It also has been described that psychopathology may influence and increase pain intensity, dysfunction and disability $(72,73)$. Anxiety and depression also have been found to decrease pain threshold tolerance and successful outcomes (74-77). In addition, anxiety and depression have been described in association with magnification of medical symptoms, whereas, emotional distress has been linked to physical symptoms by means of autonomic arousal, vigilance, and somatic amplification $(3,78-80)$.

Strong associations between psychometric scores and various aspects of behavior related to back pain and other painful conditions, abnormal psychosocial characteristics, do not prove the causal relationship between chronic low back pain and psychological abnormalities $(70,81,82)$. On the contrary, some argue that depression, antisocial attitudes, and litigation are not only normal human life experiences or phenomena but merely reflect normal reactions to vague diagnoses, ineffective treatment, poor health care, or poor relations between employee and employer (7). Thus far, there has not been a proven cause-and-effect relationship at least between chronic low back pain and psychological abnormalities $(36,65,66,70,83,84)$. Interpretation by various groups only reflects personal philosophies and biases. Thus, the existing literature and its findings are inconclusive, and not straightforward due to multiple and confounding variables including; previous experiences of pain, methodological difficulties and flaws, statistical flaws, inclusion of subpopulations in the selection groups without control groups, and poor participation by patients. It should also be realized that there is no so-called objective evaluation in psychological assessment, as all types of assessments are subjective self-reports.

\section{DEPRESSION}

Depressive disorders encompass major depressive disorder, dysthymic disorder, and bipolar disorder $(85,86)$. In addition, depressive disorders often co-occur with anxiety disorders, as well as substance abuse relevant to interventional pain practices (28). Of additional interest to interventional pain physicians is the fact that major depressive disorder is the leading cause of disability in the United States.

The association between chronic pain and depression remains a complex issue. Depression associated with chronic pain may refer to a temporary bad mood, a reaction to concurrent stress or loss, a chronic state of dysthymia, or major depression. Thus, one should distinguish between depressed mood and clinical syndrome of depression. Major depression is characterized by 2 weeks or more of either sustained and pervasive sad mood, or loss of interest and pleasure in everyday life. Accompanying these features are at least four of the following: change in weight, sleep disturbance, psychomotor agitation or retardation, fatigue, guilty ruminations, difficulty thinking, or concentrating, and recurrent thoughts of death or suicide. Dysthymic disorder is a chronic form of depression lasting 2 years or longer. Individuals with dysthymia are at high risk of developing major depression as well. The combined condition of dysthymia and major depression is often called double depression. Dysthymia is more challenging than major depression to identify in chronic pain patients. The poor sleep, the poor concentration, and lack of enjoyment often experienced by chronic pain patients are frequently attributed to pain rather than depression, also known as reactive form of depression (2). However, since they are not direct physiological effects of pain, these symptoms should count towards depression (2). Tables 1 and 2 illustrate the salient features of major depression, and dysthymia (86). Major depressive disorder is the most common psychopathology related to chronic pain (87-99).

Depression is a common phenomenon associated with all 


\section{Table 1. Salient features for diagnosis of major depression}

i. Presence of five (or more) of the symptoms during the same 2-week period. At least one of the symptoms is either (1) depressed mood or (2) loss of interest or pleasure.

(1) Depressed mood most of the day, nearly every day;

(2) Markedly diminished interest or pleasure in all, or almost all, activities most of the day, nearly every day;

(3) Significant weight loss when not dieting or weight gain eg, a change of more than 5\% of body weight in a month), or decrease or increase in appetite nearly every day;

(4) Insomnia or hypersomnia nearly every day;

(5) Psychomotor agitation or retardation nearly every day (observable by others, not merely subjective feelings of restlessness or being slowed down);

(6) Fatigue or loss of energy nearly every day;

(7) Feelings of worthlessness or excessive or inappropriate guilt (which may be delusional) nearly every day (not merely self-reproach or guilt about being sick);

(8) Diminished ability to think or concentrate, or indecisiveness, nearly every day;

(9) Recurrent thoughts of death (not just fear of dying), recurrent suicidal ideation without a specific plan, or a suicide attempt or a specific plan for committing suicide;

ii. Significant distress or impairment in social, occupational, or other important areas of functioning.

iii. Symptoms are not due to the direct physiologic effects of a substance or general medical condition.

iv. The symptoms are not accounted by bereavement and persist for longer than 2 months or are characterized by:

1) Marked functional impairment,

2) Morbid preoccupation with worthlessness,

3) Suicidal ideation,

4) Psychotic symptoms, or

5) Psychomotor retardation.

Adapted and modified from DSM - IV (86)

types of chronic pain. Manchikanti et al (37) showed the presence of major depressive disorder in $22 \%$ of the population with chronic pain compared to only $4 \%$ of the population in psychologically healthy individuals without pain. Overall, research suggests that from $40 \%$ to $50 \%$ of chronic pain patients suffer from depression. In the majority of cases, depression appears to be patient's reaction to their plight. Some have suggested that chronic pain is a form of masked depression; although this may be true in a small number of cases, the research on this topic does not suggest that depression precedes the development of chronic pain $(32,87)$. However, depression has probably been the emotion to receive the most empirical investigation $(32,87$ 99). A number of reviews of the relationship between chronic pain and depression have been published $(32,88$, 89). Differences in the definition of depression, population sample, and measurement issues have resulted in considerable variability and prevalence, with estimates ranging from $10 \%$ to $100 \%$ (88). However, in spite of multiple inconsistencies, all the estimates have almost universally indicated higher rates of depression in patients with chronic pain when compared to the general population (88). Banks and Kerns (88) compared the prevalence of depression in chronic pain with rates and other medical conditions and suggested that chronic pain sufferers may have higher rates, though the authors are cautious about drawing definite conclusions from the literature. They have estimated $30 \%$ to $54 \%$ prevalence of depression in clinicbased chronic pain samples with depression being clearly indicated as a significant issue in pain sufferers. It was also estimated that patients with two or more pain complaints were much more likely to be depressed than those with a single pain complaint (2). In addition, the number of pain conditions reported was a better predictor of major depression than was pain severity or pain persistence (2).

In a study using a structured clinical interview of 200 patients with chronic low back pain, Polatin et al (34) showed that incidence of major depressive disorder had a point prevalence of $45 \%$ and a lifetime prevalence of $64 \%$. However, bipolar disorder and dysthymic disorder were 


\section{Table 2. Salient features and diagnostic criteria of dysthymia}

i. Depressed mood for most of the day, for more days than not, for at least 2 years.

ii. Presence, while depressed, of two (or more) of the following:

(1) Poor appetite or overeating

(2) Insomnia or hypersomnia

(3) Low energy or fatigue

(4) Low self-esteem

(5) Poor concentration or difficulty making decisions

(6) Feelings of hopelessness

iii. No symptom-free interval during 2 years for more than 2 months at a time.

iv. No major depressive episode has been present during the first 2 years of the disturbance.

v. Never a manic episode, mixed episode, or hypomanic episode, and criteria have never been met for cyclothymic disorder.

vi. A disturbance that does not occur exclusively during the course of a chronic psychotic disorder, such as schizophrenia or delusional disorder.

vii. Symptoms that are not due to the direct physiological effects of a substance or a general medical condition.

viii. Symptoms that cause clinically significant distress or impairment in social, occupational, or other important areas of functioning.

Adapted and modified from DSM - IV (86)

present only in $2 \%$ of the population each. Kramlinger et al (100) showed that current major depressive disorder rates were $25 \%$, which was definite; and they also showed that the probable prevalence was 39\%. Manchikanti et al (4), in evaluating characteristics of chronic low back pain in 200 patients in a specialized setting of interventional pain management, showed that major depression was present in $23 \%$ of the patients, with $20 \%$ in men and $26 \%$ in women. However, dysthymia was present in $30 \%$ of the patients, even more common than major depression, occurring in $32 \%$ of the men and $29 \%$ of the women.

The association between migraine and depression have been noted. Breslau and Davis (90) showed that $20 \%$ to $30 \%$ of patients suffering with migraine, compared to $10 \%$ of persons without migraine, have a lifetime prevalence of major depression. Breslau et al (91) also showed that not only migraines increase the risk of subsequent development of major depression with a relative risk of 4.8 , but also that the presence of major depression increases the risk of subsequent development of migraine with a relative risk of
3.8. Thus, Breslau et al (91) postulated that major depression is not always simply a reaction to recurrent, disabling migraine episodes, but it has been interpreted as suggesting a common genetic vulnerability for migraine and depression.

\section{Relationship of Depression with Chronic Pain}

Several studies have been published using longitudinal methodology to allow for temporal and directional inferences about the nature of the relationship between depression and pain. Moldofsky and Chester (93) in 1970 using a sample of 16 patients suffering with rheumatoid arthritis, performed a longitudinal psychosomatic study, collecting measures of joint pain and responses to adjectives describing emotional states twice daily for an average of 36 days. They reported that there were two distinct subgroups, each with different patterns of pain and negative emotions which included anxiety, hostility, and depression. Von Korff et al (92) in 1993, examined whether the onset of five common pain symptoms were associated with baseline 
depressive symptoms, using a 3-year prospective design. Depression was assessed with a Symptom Checklist-90 Depression Subscale in 1,016 participants who were members of a large northwestern health maintenance health organization. This analysis showed that over the period of three years, the onset risk for headache and chest pain for individuals with moderate or severe depression ranged from 1.7 to 5.0. Baseline depressive symptoms were not predictive of the occurrence of back pain, abdominal pain, or temporomandibular joint pain. However, no consistent effect for severity of depression was observed. They also noted that presence of a pain condition at baseline was a more consistent predictor of subsequent pain onset than depressive symptoms.

The association between migraine headaches and major depression was demonstrated by Breslau et al (94). They collected data over a 3.5 years in a longitudinal design with a sample of 1,007 young adults from a large health maintenance health organization. They showed that the relative risk for major depression associated with prior migraine was 3.2 and that the relative risk of migraine associated with previous major depression was 3.1. They concluded that their results suggested by directional influence of depression and migraine headaches $(91,94)$. Even though migraine headaches could be considered a somewhat unique variant of chronic pain, similar factors may operate in the temporal relationship between negative emotion and other painful conditions. Leino and Magni (95) assessed the relationship between symptoms of distress and musculoskeletal symptoms on three occasions at 5-year intervals in 607 Finnish industrial workers. They showed that the general emotional distress scores from an earlier assessment were positively related to selfreport of musculoskeletal symptoms. However, they were unable to show any association between the development of musculoskeletal symptoms and depression.

Brown (96) also addressed the temporal relationship between pain and depression in 243 patients diagnosed with rheumatoid arthritis. They showed that with depression from the previous period controlled, the cross-time regression path for pain predicting depression was positive and modest in magnitude for the second 12-month period but not for the first 12-month period. However, pain was not predicted by prior episodes of depression when the effect of previous pain was removed. Magni et al (97) found that chronic pain patients were 2.85 times more likely to report depression at follow-up eight years later, whereas the risk ratio for the prediction of chronic pain from depression symptoms was 2.14 . They also suggested that the hypothesis of whether chronic pain causes depression or depression causes chronic pain may not be mutually exclusive. They speculated that depression may be more predictive of some pain conditions and that certain pain conditions may be more likely to predict depressive symptoms.

Polatin et al (34) evaluated psychopathology in 200 chronic low back pain patients and found that, in $55 \%$ of the patients who had concurrent major depressive disorder, it developed before the onset of chronic pain. They also showed that $45 \%$ of the patients became depressed after the onset of chronic pain. Mannion et al (35) evaluated 403 volunteers with no history of "serious" low back pain (defined as pain requiring medical attention or absence from work) who participated in a functional spinal assessment along with psychological assessment. They compared the scores obtained when individuals first reported back pain with the scores obtained 6 months previously. Seventy-nine participants reported "serious" low back pain as defined previously, and 162 reported "any" back pain within the 18-month follow-up period. Modified Somatic Perception Questionnaire (MSPQ) scores increased slightly after "serious" back pain was experienced, but only in a manner similar to that observed between the initial and 6-month assessments in individuals who had experienced no low back pain. No significant changes were seen in any of the scores following a report of any back pain. Any back pain that was experienced on the day that the questionnaire was completed was associated with an increased Zung score. The authors reported that the most significant predictor of "serious" and "any" back pain was previous back pain, even though this was considered "nonserious." They also reported that workload had no effect on the risk of back pain, regardless of whether the workload was a self-rated assessment of job heaviness, or specified on the basis of job description. In addition, they reported that, as age of the participant and number of years spent in health care increased, the risk of "any" back pain decreased. The annual incidence of serious back pain in the first 12 months of the study (35) was similar to the $16 \%$ reported previously in a large prospective study on a general population (36). Mannion et al (35), on the one hand, showed that psychological test scores have relatively little use in predicting the occurrence of first-time back pain. On the other hand, they concluded that scores on the MSPQ and Zung questionnaires, which essentially measure somatic anxiety and depression, were significant predictors of first-time low back pain in a population of young healthcare workers. They also concluded that these scores showed good reproducibility over a period of 18 months 
and were affected little by back pain, so it appears that abnormal psychometric scores do precede back pain in some people. They stated that none of the six types of psychometric scores evaluated was able to predict, either by itself or in combination with other test scores, more than $3 \%$ of first-time low back pain. Thus, the authors correctly point out that, even though they incorrectly concluded that psychological variables play an important role in explaining how people respond to back pain, they are much less important in explaining the initial onset of pain.

\section{Influence of Depression on Pain}

Fishbain et al (32), in a meta-analysis of previous studies of chronic pain and depression, found that 21 of 23 articles related the severity of pain to the degree of depression. In addition, the duration of pain was also related to the development of depression in three of three articles that included patients with multiple types of symptomatology. Von Korff and Simon (33) studied patients from primary care practices and found that the degree to which pain interfered with daily function was associated with the severity of depression, and the number of pain days and the number of pain sites was also highly related to the degree of depression. Similarly, Fishbain et al (32) also reported that the number of pain sites was related to the degree of depression in both of the two studies that investigated this issue. Thus, Rush et al (5) concluded that there are clear relationships between the degree of depression and chronic pain. They also concluded that the severity of depression is related to the presence of pain, duration of pain, severity of pain, number of pain sites, frequency of pain, intrusion of pain into daily experience, and breakthrough pain symptomatology. However, in patients who have depression and chronic pain, if the pain is alleviated, the depression also improves (101-104).

\section{Depression and Impairment}

Penninx et al (105), in a large study of 6,247 patients with 6 years of follow-up that included patients with and without depression, showed that the relative risk of impairment and activities of daily living was 1.67 times higher for those with depression than for those who were not depressed. They also showed that the relative risk for mobility impairment was 7.73 times higher in those with depression, which indicates that those with depression may have a marked decrease in their physical daily activity and deconditioning and that musculoskeletal dysfunction may then develop (5). Rush et al (5) noted that there is a substantial association between the degree of physical activ- ity and the presence or absence of depression. They concluded that those with higher physical activity had a somewhat reduced risk for depression compared with those with low physical activity, who had a greater risk.

\section{Familial Relationship}

Many forms of recurrent depression are genetic or familial (5). Magni (101) reported that $38 \%$ to $69 \%$ of the patients with chronic pain have one or more affected firstdegree relatives. Krishnan et al (106) also have reported increased incidence of depression and "depressive spectrum" disorders in families of patients with chronic pain. Rush et al (5) reported that, given that many patients with chronic pain have pre-existing depression, they may be genetically predisposed to chronic pain as a result of their depression.

\section{Depression and Physical Response}

Flor et al (107) postulated that poor coping resources for managing stressful situations, coupled with depressed mood, place individuals at risk for developing excessive muscle-tension responses to pain. They also showed some research evidence that only those patients who were depressed, worried, and emotionally affected by their pain were likely to show high levels of low back muscle tension in response to stress. Weisberg et al (108) showed very high levels of bilateral trapezius muscle tension in depressed patients when they were exposed to the stressor, whereas non-depressed patients exposed to the same stressor showed relatively little muscle-tension response. Depression has been reported to cause magnification of physical or medical symptoms, increase in pain intensity, and reduction in successful outcomes.

In summary, it is clear that prolonged pain is associated with increased depression, that depression becomes more common after the onset of the pain; and that, for at least chronic low back pain, depression may precede or follow the onset of pain (5). In addition, there is a group of patients with chronic pain who have family members with significant mood disorders, typically major depression, and may therefore be at a higher risk for chronicity of pain symptoms. Thus, it is clear that depression and chronic pain occur together; whether they are causal, coincidental, mutually exacerbating or synergistic is not entirely clear (5). Based on current studies, the risk for major depression is higher with chronic pain than with other general medical conditions (5). Based on the experience with major depressive disorder and worsening of the prognosis 
of most general medical conditions, it is highly likely that such is the case with chronic pain (5). In fact, Waddell et al (109) have reported that patients with low back pain who have higher degrees of expressive distress tend to receive significantly more treatment interventions, but with lessersuccess.

\section{ANXIETY DISORDERS}

Anxiety disorders include not only generalized anxiety disorder, which is the most common form of anxiety, but also panic disorder, obsessive/compulsive disorder, posttraumatic stress disorder, and phobias. Approximately $13 \%$ of the adult population in the US are expected to have an anxiety disorder in a given year (27). Anxiety disorders frequently co-occur with depressive disorders, eating disorders, or substance abuse $(28,29)$. Many people have more than one anxiety disorder (110). Women are more likely than men to have an anxiety disorder and other related disorders (110-112). It is not uncommon or unusual for patients with pain to be anxious and worried. However, anxiety and concern about symptoms are not synonymous with a diagnosis of generalized anxiety disorder. Generalized anxiety disorder, commonly seen in chronic pain not only influences the pain pattern, but also recovery and subsequent disability. Additionally, most often chronic pain patients also meet the diagnostic criteria for a depressive disorder. Panic disorder also is a common, disabling psychiatric illness. It is associated with numerous medically unexplained symptoms and high utilization of medical services. Panic disorder is most commonly associated with headaches, chest pain, and abdominal pain (2). Lifetime prevalence of panic disorder is estimated to be $1.5 \%$ to $3.5 \%$, with a one year prevalence of $1 \%$ to $2 \%$. The salient features of generalized anxiety disorders are shown in Table 3.

\section{Table 3. Salient features and diagnostic criteria of generalized anxiety disorder}

i. Excessive anxiety and worry (apprehensive expectation), occurring more days than not for at least 6 months, about a number of events or activities (such as work or school performance).

ii. Difficulty in controlling worrying.

iii. Anxiety and worry associated with three (or more) of the following six symptoms (with at least some symptoms present for more days than not for the past 6 months):

1. Restlessness or feeling keyed-up or on edge

2. Being easily fatigued

3. Difficulty concentrating or mind going blank

4. Irritability

5. Muscle tension

6. Sleep disturbance (difficulty falling or staying asleep, or restless, unsatisfying sleep)

iv. The focus of the anxiety and worry not being confined to features of an Axis I disorder, eg, Panic disorder

Social phobia

Obsessive/compulsive disorder

Separation anxiety disorder

Somatization disorder

Hypochondriasis

Posttraumatic stress disorder.

v. Anxiety, worry, or physical symptoms that cause clinically significant distress or impairment in social, occupational, or other important areas of functioning.

vi. The disturbance not being due to the direct physiological effects of a substance or a general medical condition 
It is somewhat difficult to calculate the prevalence of generalized anxiety disorder due to a larger range of anxiety diagnoses. Nonetheless, the role of anxiety in pain has received considerable attention. Asmundson et al (113) showed that $18 \%$ of the patients with chronic musculoskeletal pain were diagnosed with a current anxiety disorder. Atkinson et al (114) compared patients with low back pain to a matched sample of pain-free men and found that the chronic pain groups had significantly higher lifetime prevalence rates of major anxiety disorder (31\% versus 14\%). Manchikanti et al (37) showed generalized anxiety disorder to be present in $40 \%$ of the population with chronic pain compared to $14 \%$ in psychologically healthy population without chronic pain. Manchikanti et al (4) showed that, in the sample of 200 patients with chronic low back pain, $49 \%$ presented with a diagnosis of generalized anxiety disorder, which was the most common diagnosis, with no differences noted among men and women. Polatin et al (34) showed that generalized anxiety disorder was present in only $2 \%$ of patients, whereas phobic disorder was present in $9 \%$, with panic disorder in $3 \%$ and obsessive/compulsive disorder in $2 \%$.

Similar to depression, Moldofsky and Chester (93), in a longitudinal psychosomatic study, showed that there were two distinct subgroups, each with different patterns of pain and negative emotion. They showed that the first group was characterized by increases in pain that were preceded by elevations in anxiety and hostility. In contrast, the second group displayed an inverse temporal relationship between pain and a hopelessness/helplessness dimension.

Thus, even though there is diagnostic variability within this area, which makes definitive statements about prevalence somewhat difficult, the data appear to be clear that anxiety plays a strong role in the experience of chronic pain. In addition, avoidance of activity due to fear is also postulated to result in chronic pain conditions characterized by a cycle of decreased activity, deconditioning, loss of self-efficacy, fear, and negative affect, leading to further avoidance of pain-related activities (115).

\section{STRESS}

Stress is commonly seen in patients suffering with chronic pain. Stress is a normal human emotion that is part of everyday living. Stress is rather a positive effect, as that is how human beings become energized; and a certain level of stress is necessary for human beings to perform at their best (7). However, too much stress can be unproductive worsening human performance rather than making it bet- ter. Thus, it is essential to differentiate between stress and distress. While stress is a normal human emotion in response to life, distress is an excessive or abnormal stress response (7). The common underlying characteristic of stress is a feeling of being under pressure or feeling overwhelmed. Other symptoms and signs of stress are described in Table 4.

People react to stress in different ways. The most common emotions are anxiety, depression and anger (7). These are not mutually exclusive, and some patients show features of all of these (7). While some patients show features of all emotions, some show these selectively. Thus, clinically, psychological distress is defined as a disturbance of emotion and mood in which psychologic and physical symptoms occur (7). Croft et al (116) evaluated psychologic distress associated with back pain in the general population and found that $15 \%$ to $30 \%$ of people with back pain may have some degree of distress, sufficient to influence their pain and physician visits. Back pain itself is a very powerful stressor. However, there may be other, unresolved difficulties that are confounding the problem of back pain (7). Main and Waddell (7) reported three types of stress history which may merit special attention. First, a small but important group of chronic low back pain patients have a history of physical and sexual abuse, either in childhood or as part of their continuing problem. Even though clinicians generally believe that abuse is more common in women, it appears that similar problems are not uncommon in men. Secondly, if patients have been involved in a serious injury, they should be evaluated for post-traumatic stress symptoms. Post-traumatic stress symptoms include events outside the usual range of experience that would markedly distress almost anyone, persistent re-experiencing of the traumatic event, avoiding

Table 4. Salient feature of stress

Chronic fatigue

Loss of interest and enjoyment

Difficulty concentrating

Irritability and impatience

Anxiety

Withdrawal

Muscle tension

Aches and pains

Difficulty sleeping

Change in appetite

Trembling, and sweaty hands

Adapted and modified from Main and Waddell (7) 
thoughts or activities associated with the trauma, experiencing symptoms of physiologic arousal and psychologic distress, and having a duration of symptoms for more than 1 month. Thirdly, some patients may have become distressed about seeing doctors or other health professionals due to opinions from a whole range of professionals which may even be contradictory. These patients also have been told that their pain is imaginary or that it is in their heads. Such experience colors and shapes the patients' attitude towards physician consultations. In addition, they may be angry.

In chronic pain, anxiety and stress are only some of several emotions and may not reach a stage of anxiety neurosis in many patients. The salient features of anxiety include apprehension, doubt about ability to cope or achieve, loss of ability to take responsibility and increase in dependence on others, feeling of tension, and difficulty with concentration. Patients describe their anxiety with feelings of being "tense," "wound up" or "on edge" (Table 3). Some may have physical signs of tachycardia, excessive sweating, dry mouth and tremor. Some patients may describe their symptoms dramatically as "butterflies in the stomach," "shortness of breath" or "choking."

Post traumatic stress disorder also has been associated with chronic pain. Post traumatic stress with or without pain is a common phenomenon in Vietnam veterans, Gulf War veterans, in patients following motor vehicle injuries and in patients with childhood abuse.

Apart from the above symptomatology, patients may have increased bodily awareness, and fears and uncertainty, as well as anger. Increased bodily awareness is described as a heightened emotional state which produces sensitization to bodily sensations and physiologic events (7). Main (117) assessed patients with back pain in an orthopedic outpatient clinic. He reported that patients were clearly anxious and concerned about their pain. Patients also described symptoms of increased sympathetic activity and heightened concern about their physical symptomatology. However, very few of them met criteria for either anxiety neurosis or hypochondriasis. Thus, Main (117) developed the MSPQ to measure increased bodily awareness. This questionnaire measures a person's symptoms and signs or bodily awareness by assessing how much bodily awareness he/she felt during the past week at four levels: not at all, a little/slightly, a great deal/quite a lot and extremely/ could not have been worse. The questions include experiencing an increase in heart rate; feeling hot all over; sweating all over or sweating in a particular part of the body; feeling a pulse in the neck or a pounding in the head; experiencing dizziness or blurred vision; feeling faint, feeling that everything appears unreal; experiencing nausea, butterflies in the stomach, pain or ache in the stomach, stomach churning, or a desire to pass water; feeling dryness in the mouth or having difficulty swallowing; aching in a muscle in the neck; feeling weak in the legs; twitching or jumping in the muscles; a tense feeling across the forehead and a tense feeling in jaw muscles. However, only 13 items are scored and added to give a total score, which ranges from 0 to 3 . The MSPQ has been commonly used to assess somatization, as well as anxiety; even though it mainly measures increased bodily awareness, along with increased sympathetic activity.

Many patients with chronic pain, similar to physicians treating chronic pain, not only get angry, but also get frustrated. There are no studies reporting the relationship between anger, chronic pain and outcomes; however, anger may lead to failed treatment, which then makes the patient more angry, trapping him/her in a self-perpetuating rut of failure and frustration, which may also be transferred to the physician.

\section{SOMATIZATION}

Somatization disorder is not only a complex disorder, but also a complicated and controversial psychiatric diagnosis. Aronoff et al (40) defined somatization as not being the psychiatric diagnosis of somatization disorder, formerly known as Briquettes syndrome. In order to meet the full criteria of somatization disorder, a patient must have a history of many physical complaints beginning before age 30 , which occur over a period of several years and result in his/her seeking treatment or significant impairment in social, occupational, or other important areas of functioning. In addition, the patient must also have four pain symptoms, two gastrointestinal (GI) symptoms, one sexual symptom, and one pseudoneurologic symptom. Further, a patient with somatization and pain disorder also should meet the criterion that after appropriate physical investigation, each of the previously named symptoms cannot be fully explained by a known general medical condition or by the direct effects of a substance; only then criteria for somatization disorder are considered to have been met (86).

In order to diagnose a patient with somatization disorder when there is a related general medical condition, the physical complaints or the social or occupational impairments that result from the general medical condition should be in excess of what would be expected from history, exami- 
nation or laboratory findings (40). Lipowski (118) conceptualized somatization as a "tendency to experience and communicate somatic distress and symptoms unaccounted by pathologic findings, to attribute them to physical illness, and to seek medical health for them." Sullivan and Katon (45) defined somatization as, "An ubiquitous and diverse process linking the physiology of distress and psychology of symptom presentation" in a primary care setting. Aronoff (119) viewed somatization with the perspective of Sullivan and Katon (45) when discussing pain conditions such as myofascial pain syndromes or fibromyalgia.

Psychophysiologic, as well as psychosomatic responses, may be present with somatization disorder, even though the two terms are not interchangeable. Aronoff et al (40) described that, in a psychosomatic response, a patient's psychological state interacts with certain predisposed physical vulnerabilities, such as in the development of an ulcer. In contrast, in a psychophysiologic response, which is more commonly seen with individuals without the requirement of a physical predisposition, individuals experience a tension-type headache or GI upset. In addition, somatization is also a likely process occurring within a pain disorder itself.

Patients with a tendency towards somatization may present to the physicians' hoping to obtain medical attention and symptomatic treatment. This tendency essentially begins in childhood and is believed to account for a significant proportion of medical care utilization in adults. These patients are described as being heterogeneous and present with an assortment of unexplained symptomatology; psychosocial distress; and psychophysiologic syndromes such as irritable bowel syndrome, chronic pain, hypochondriac worry, a history of sexual and physical abuse and bodily manifestations of psychiatric disorders. These patients are frequently labeled as "somatizers," not based on specific symptom presentations; but because they repeatedly seek the counsel of physicians in search of understanding, although no satisfactory medical explanations can be found. Fink et al (41) showed that between $22 \%$ and $58 \%$ of the consecutive patients in primary care fulfilled the diagnostic criteria for a somatoform disorder. They correlated this with the prevalence of mental disorders in primary care patients, which was described as $14 \%$ and $36 \%$ (42, 43).

Some patients may prefer to report somatic symptoms over psychosocial concerns because they believe they will receive more medical attention, but others may simply experience distress somatically (40). However, the connec- tion between symptoms and life events is often not immediately evident to the patient or the physician (120). The reasons described as encouraging patients with psychological symptoms to present with somatic features include poor insight of the patients into their own emotional status (121). The medical community responds more sympathetically to physical rather than psychological distress, and insurance reimbursement patterns encourage the expression of illness versus psychological distress (47).

In specific reference to somatization in chronic patients, Sullivan and Katon (45) based on the review of family medicine studies, claimed that patients with chronic nonmalignant pain tend to have multiple non-pain physical complaints The literature indicates that these symptoms account for $30 \%$ to $40 \%$ of ambulatory medical visits, with only a small percentage of these patients having an identifiable organic etiology (122). Review of studies on pain in the literature also showed a high percentage of chronic pain patients' demonstrating elevated hypochondriasis scores (123) and somatization scores (124), as measured by the illness behavior questionnaire and the MSPQ, respectively. In addition, when patients with various types of chronic pain were compared with appropriate controls on somatization measures, the chronic pain patients were frequently shown to have greater somatization scores (44). This has been true for chronic low back among other painful conditions (124). Salient features of somatization are illustrated in Table 5.

It has been argued that with chronic pain, there may be a sensitizing effect to physiological events that heightens bodily awareness (98). It also has been stated that chronic pain patients blur painful and non-painful experiences and interpret a wide variety of experience in terms of pain, particularly affective distress (99). It is also presumed that somatization is related to both pain symptoms and depressive complaints.

Further, questions have been raised as to whether there is a relationship between somatization, secondary gain and pain. Fishbain et al (125) found only two studies (126, 127) that can be construed to address the relationship among secondary gain, somatization, and chronic pain. Cassisi et al (127) studied 250 patients, utilizing the Symptom Checklist (SCL-90) and showed that all patients had elevated SCL-90 scores; but Workers' Compensation patients demonstrated the highest level of somatization. Korbon et al (126), in contrast, studied patients with Workers' Compensation injuries, utilizing a somatic amplification rating scale which is designed to quantify nonorganic 
Table 5. Salient features and diagnostic criteria of somatization disorder

i. A history of many physical complaints:

beginning before age 30 years that occur over a period of several years and result in treatment being sought, or

significant impairment in social, occupational, or other important areas of functioning.

ii. Each of the following criteria must have been met, with individual symptoms occurring at any time during the course of the disturbance:

(1) Four pain symptoms a history of pain related to at least four different sites or functions (eg, head, abdomen, back, joints, extremities, chest, rectum, during menstruation, during sexual intercourse, or during urination)

(2) Two GI symptoms a history of at least two GI symptoms other than pain (eg, nausea, bloating, vomiting other than during pregnancy, diarrhea, or intolerance of several different foods)

(3) One sexual symptom: a history of at least one sexual or reproductive symptom other than pain (eg, sexual indifference, erectile or ejaculatory dysfunction, irregular menses, excessive menstrual bleeding, vomiting throughout pregnancy)

(4) One pseudoneurological symptom: a history of at least one symptom or deficit suggesting a neurological condition not limited to pain (conversion symptoms such as impaired coordination or balance, paralysis or localized weakness, difficulty swallowing or lump in throat, aphonia, urinary retention, hallucinations, loss of touch or pain sensation, double vision, blindness, deafness, seizures; dissociative symptoms such as amnesia; or loss of consciousness other than fainting)

iii. Either (1) or (2):

(1) After appropriate investigation, each of the symptoms in Criterion ii cannot be fully explained by a known general medical condition or the direct effects of a substance

(2) When there is a related general medical condition, the physical complaints or resulting social or occupational impairment are in excess of what would be expected from the history, physical examination, or laboratory findings

iv. The symptoms are not intentionally produced or feigned.

Adapted and modified from DSM - IV (86)

physical findings that indicate either conversion problems or malingering. They found that chronic pain patients with high somatic amplification-rating-scales scores were significantly more likely to be Workers' Compensation patients suffering with chronic pain.

Manchikanti et al (37) assessed prevalence of somatoform disorder in chronic pain patients comparing to psychologically healthy normal individuals without chronic pain showing $0 \%$ incidence of somatoform disorder in nonpain patients compared to $26 \%$ in pain patients utilizing MCMI-III evaluation.

Manchikanti et al (4), in evaluating characteristics of chronic low back pain in patients in an interventional pain management setting, showed that of the 200 patients included in the study, patients presenting to an interventional pain medicine setting are different from those presenting to either a neurosurgical or orthopedic surgical setting. Somatization disorder was seen in $34 \%$ of patients, with no significant difference between men and women.

Sikorski et al (49), evaluating the psychological aspects of chronic low back pain in a structured, prospective study, determined the prevalence of somatization in a sample of 3100 patients with chronic low back pain using the Illness Behavioral Questionnaire (IBQ) and the MSPQ. They showed that $54 \%$ of the patients had four or more out of five abnormal illness indicators. The MSPQ values for the group were significantly above the control values in the literature. They also showed that $32 \%$ of pain diagrams were thought to be incompatible with an organic cause when assessed by an orthopedic surgeon and $62 \%$ when assessed by a psychiatrist. However, as described 
earlier, the MSPQ was developed to assess body awareness and it does not specifically assess somatization disorder.

While it is not known in general in chronic pain, the incidence of higher levels of somatization in chronic low back pain patients has not been shown to translate into poor prognosis or false-positive results on diagnostic testing. Multiple reports have shown (102-104) improvement in psychological status following appropriate diagnosis and treatment of the painful condition. Block et al (128) evaluated the influence of psychological factors and discographic pain report. The significance of psychosocial factors in low back pain has been repeatedly demonstrated in the literature (129). It has been shown that elevated scores on the Minnesota Multiphasic Personality Inventory (MMPI) hypochondriasis (HS) and hysteria (HY) scales have been found to predict the occurrence of job-related low back pain (65). In addition, the same characteristics, as well as other features assessed by the MMPI, have predicted a poor response to surgery, and also to conservative care $(130,131)$. However, somatization has not been studied specifically in these disorders. Among chronic back pain patients, the most frequently found MMPI profiles are those containing elevated HS and HY scales (132). These profiles in general reflect excessive bodily concern, but without much emotional distress, the same variables assessed by the MSPQ. These patients with these profiles may "have multiple somatic complaints including headaches, chest pain, back pain and numbness or tremors of the extremities which increase in times of stress" (133). Thus, it is postulated that, if chronic low back pain patients are oversensitive to pain and other physical symptoms, poor treatment outcome may result. Bacon et al (124) concluded that $26 \%$ of chronic low back pain patients met strict DSM-III criteria for a lifetime diagnosis of somatization disorder, reporting a lifetime history of 12 or more symptoms, compared to only $4.4 \%$ of controls. They also reported that major depression and alcohol dependency were significantly associated with increased severity of somatization and increased impairment; however, pain intensity was not related to greater somatic complaints. They concluded that symptoms of somatization are prevalent, but not chronic low back pain; and the pattern of these symptoms is reminiscent of the spectrum reported in other medical populations.

Manchikanti et al (38) showed that, in two distinct groups of patients with or without somatization, there was no difference in provocative discography between groups ( $44 \%$ somatization vs $48 \%$ non-somatization). These results contradicted the results of Carragee et al (134), who, with provocative discography, postulated that somatization can produce false-positive results in patients without back pain. However, Manchikanti et al (38) evaluated patients with a definite diagnosis of somatization disorder or its absence by a valid and more elaborate psychological testing, resulting in a comprehensive evaluation. Manchikanti et al (39) also demonstrated that somatization failed to influence the ability (with diagnostic facet joint nerve blocks), to diagnose facet joint pain. Facet joints were shown to be a source of chronic low back pain in $44 \%$ of the patients without somatization and $38 \%$ of the patients with somatization.

\section{DRUG DEPENDENCE}

Drug dependence, substance abuse, and overuse of controlled substances, as well as abuse of alcohol and street drugs, are common problems in chronic pain management, including interventional pain management. Chronic pain patients with protracted pain experience and symptoms eventually rely on opioids for pain relief, other controlled substances for other symptom control, and occasionally to improve functional ability. Drug dependence and drug abuse are becoming extremely common problems in interventional pain medicine. Polatin et al (34) also showed substance abuse in $19 \%$ of the patients with low back pain. In a study evaluating controlled substance abuse, Manchikanti et al (135) showed opioid abuse in $24 \%$ of the patients in an interventional pain medicine setting. However, drug therapy is one of the most commonly used modalities of treatment in managing persistent or chronic pain. Controversy continues with regards to use of controlled substances, specifically opioid analgesics, in managing chronic or recurrent pain. The fear of addiction from using opioids for chronic pain goes back to the early 1800 s (136). Even though opioids have long been accepted as appropriate for the management of acute and cancer pain, physicians and healthcare professionals are reluctant to support the use of opioid medication for patients with chronic pain because of concerns they have about efficacy, adverse effects, tolerance, and addiction (137-139). It has been estimated that approximately $40 \%$ to $90 \%$ of patients in pain treatment facilities received controlled drugs, specifically opioids. In the early 1990s, it was shown that $33 \%$ of the population of the United States sampled illicit drugs (143), and as many as $15 \%$ had a substance use disorder of some type (144). Fishbain et al (145), studying drug abuse and dependency in chronic pain patients, concluded that approximately between $3 \%$ and $19 \%$ of the patients have been diagnosed with a substance 
abuse disorder. Polatin et al (34) also showed that while current substance abuse was $19 \%$ in chronic low back pain patients lifetime prevalence was $36 \%$.

Some randomized, controlled studies have supported the efficacy of opioid treatment of patients with chronic pain (146-148). While this trial suggest that opioids can improve the level of analgesia and the quality of life in some patients, other studies suggest that some patients become psychologically dependent after long-term opioid use (149). Some investigators also believe that opioid analgesics contribute to psychological distress, poor treatment outcome, impaired cognition and a fostered reliance on the healthcare system (150-154).

\section{PERSONALITY DISORDERS}

The influence of personality on the pain experience has long interested clinicians working with individuals having chronic pain (50). Many of the early theories of chronic pain maintain that personality plays an important role in the development and maintenance of chronic pain conditions $(50-55,155)$. The early psychological literature on chronic pain focused on the relationship of personality to pain, and significant writings about personality and pain were based on a model of personality that emphasized the influence of personality traits or dispositions that are present not only in chronic pain patients, but also in the population at large (50). Thus, in research studies, personality traits and characteristics were examined in heterogenous samples of patients having chronic pain; however, an alternative approach to examining the influence of personality and chronic pain involves careful study of those chronic pain patients who suffer from personality disorders (50). This approach is based on the notion that, within heterogeneous samples of chronic pain patients, there are homogeneous subgroups of patients who have diagnosable personality disorders characterized by longstanding, problematic behavior patterns (50). In fact, multiple studies of patients with personality disorders are considered to have led to new insights in many areas of psychiatric research (50).

The biopsychosocial model maintains that personality traits and dispositions interact with biological factors to determine how one responds to pain (156). Engel (157) in 1977 conceived the biopsychosocial model, in which he described that illness represents a complex interaction of biological, psychological, and social influences. The biopsychosocial model of pain has served as the basis for multidisciplinary treatment programs for chronic pain.
While, ideally, multidisciplinary programs for chronic pain incorporate a variety of medical, psychological, and social interventions to treat and teach patients to control their pain and resume a functionally effective lifestyle and to promote more adaptive social interactions with family, friends, and employers; the multidisciplinary approach has since then achieved a variety of techniques, including development of interdisciplinary management programs; functional rehabilitation programs; and, finally, psychosocial programs without any biomedical interventions.

Another type of biopsychosocial model is the diathesisstress model, which was proposed as an explanation to understand why some individuals develop chronic pain disorders while others do not $(158,159)$. Essentially this model postulates that chronic pain disorders are a function of the interaction between the individual's premorbid biological and psychological predispositions (diathesis) and the challenges or stressors (stress) that he or she faces as a result of physical impairment and tissue damage (160). Thus, the diathesis includes the individual's personality strengths and vulnerabilities, whereas stress includes the biochemical and nociceptive changes that occur at the outset of the pain disorder. The muscular hyperactivity that occurs in certain low back pain patients was explained on the diathesis-stress model (156).

In understanding the influence of personality on chronic pain and the response of a person to chronic pain with rehabilitation, it is important to understand the differences between personality traits and personality disorders. A number of psychological testing instruments are available for assessment of personality traits. In addition, multiple descriptive studies have attempted to identify personality traits that are common in patients having chronic pain; however, after reviewing the enormous literature, Weisberg and Keefe (156) commented that there does not appear to be any consistent evidence that chronic pain patients fit one profile, as previously believed, although some traits may be common between individuals. Similar to descriptive studies, a number of predictive studies also have examined the degree to which personality traits measured by standard psychological tests can predict the outcome of treatments for chronic pain (156). They also stated that psychological tests can provide a reliable and standardized way of assessing personality traits in patients with chronic pain. In addition, they conceded that, even though some studies have found a relationship between certain personality traits, ie, hypochondriasis, hysteria, and depression, and treatment outcome, other studies have not found evidence for such relationships. 
In contrast to personality traits, personality disorders must satisfy two criteria in order to be considered personality traits or characteristics severe enough to be a disorder (DSM-IV). These criteria include the individual's intrapsychic and intrapersonal functioning, which should be significantly different from that of his or her society or culture; and inflexibility and pervasiveness of these characteristics (50). Personality disorders, by definition, develop during childhood and become apparent in adolescence or early adulthood (DSM-IV); thus, personality disorders reflect long-standing patterns of maladaptive behaviors, thoughts, and emotions, with symptoms severe enough to interfere with the individual's daily functioning Table 6 illustrates characteristic features of various per- sonality disorders.

Several studies have attempted to examine the prevalence of personality disorders in chronic pain populations. However, the limitations of these studies include that the prevalence of personality disorders among the US population is low, ranging from less than $1 \%$ for paranoid and avoidant personality disorder to $2 \%$ to $3 \%$ for histrionic and antisocial personality disorders, even though exact incidence is not known (160). Large (161) evaluated personality disorders in 50 patients at the Aukland Pain Clinic in New Zealand, with a 11/2-to 2 -hour interview, showing that $40 \%$ of the patients met criteria for a personality disorder, with mixed personality disorder being the most common diag-

Table 6. Salient characteristics of common personality disorders

\begin{tabular}{|c|c|c|c|c|}
\hline & Intrapsychic Function/Affect & Interpersonal Function & Defense Mechanisms & Cognition/Reality Testing \\
\hline Paranoid & $\begin{array}{l}\text { irresponsible, tense, restricted } \\
\text { affect }\end{array}$ & $\begin{array}{l}\text { Suspicious,mistrustful, } \\
\text { hypersensitive }\end{array}$ & $\begin{array}{l}\text { Projection, occasional } \\
\text { ideas of reference }\end{array}$ & $\begin{array}{l}\text { Concrete,suspicious, } \\
\text { distorted }\end{array}$ \\
\hline Schizoid & Restricted affect & Withdrawn aloof & $\begin{array}{l}\text { Intellectualization, } \\
\text { splitting }\end{array}$ & $\begin{array}{l}\text { Good abstraction, intact } \\
\text { reality testing }\end{array}$ \\
\hline Schizotypal & $\begin{array}{l}\text { Out of touch with own affect, } \\
\text { constricted, anhedonia }\end{array}$ & $\begin{array}{l}\text { Poor, inappropriate, } \\
\text { interpersonal relations }\end{array}$ & Paranoid, suspicious & $\begin{array}{l}\text { Magical thoughts, } \\
\text { perceptual aberrations, may } \\
\text { have breaks with reality } \\
\text { under stress }\end{array}$ \\
\hline Antisocial & Seemingly unaware of affect & $\begin{array}{l}\text { Unable to conform to } \\
\text { social norms, } \\
\text { superficially charming, } \\
\text { manipulative }\end{array}$ & Impulsivity & $\begin{array}{l}\text { Good reality testing, } \\
\text { sometimes heightened }\end{array}$ \\
\hline Borderline & $\begin{array}{l}\text { Unstable affect, poor self- } \\
\text { image, free-floating anxiety }\end{array}$ & $\begin{array}{l}\text { Tumultuous relations, } \\
\text { overvalues/devalues } \\
\text { others }\end{array}$ & $\begin{array}{l}\text { Projection,splitting, } \\
\text { devaluation, } \\
\text { omnipotence }\end{array}$ & $\begin{array}{l}\text { Impulsivity, poor reality } \\
\text { testing at times }\end{array}$ \\
\hline Histrionic & $\begin{array}{l}\text { Poorly modulated affect, } \\
\text { insecure with oneself }\end{array}$ & $\begin{array}{l}\text { Attention-seeking, } \\
\text { dramatic }\end{array}$ & $\begin{array}{l}\text { Repression,conversion, } \\
\text { dissociation }\end{array}$ & $\begin{array}{l}\text { Impaired under stress, } \\
\text { vague, global, } \\
\text { impressionistic }\end{array}$ \\
\hline Narcissistic & $\begin{array}{l}\text { Grandiose sense of self, fragile } \\
\text { self-esteem }\end{array}$ & Exploitative of others & Entitlement & $\begin{array}{l}\text { Fantasies of success, } \\
\text { beauty, brilliance,no } \\
\text { psychotic thinking }\end{array}$ \\
\hline Avoidant & insecurity & $\begin{array}{l}\text { Desires relations but shy, } \\
\text { withdrawal at fear of } \\
\text { rejection }\end{array}$ & Vigilance & $\begin{array}{l}\text { Good reality } \\
\text { testing,occasional cognitive } \\
\text { interference }\end{array}$ \\
\hline Dependent & Self-doubt,Insecurity & $\begin{array}{l}\text { Subverts own needs to } \\
\text { those of others, needs } \\
\text { excessive advice and } \\
\text { reassurance }\end{array}$ & Submissive & $\begin{array}{l}\text { Difficulty with decision } \\
\text { making }\end{array}$ \\
\hline $\begin{array}{l}\text { Obsessive/ } \\
\text { compulsive }\end{array}$ & Emotional constriction & $\begin{array}{l}\text { Unable to compromise, } \\
\text { eager to please authority } \\
\text { figures }\end{array}$ & $\begin{array}{l}\text { Repetitive acts, } \\
\text { intellectualization }\end{array}$ & $\begin{array}{l}\text { Inflexible thought pattern, } \\
\text { ruminative, overcontrol, } \\
\text { detail-oriented }\end{array}$ \\
\hline
\end{tabular}

Adapted and modified from Weisberg and Keefe (156) 
nosis in 11 patients, or $20 \%$, followed by histrionic personality disorder in 3 , or $20 \%$, of the patients. Fishbain et al (162) in an evaluation of 283 chronic pain patients, showed that $50 \%$ of the patients met criteria for a personality disorder diagnosis. They showed that dependent personality disorder was most frequently diagnosed in $17 \%$ of the patients, followed by passive/aggressiveness in $15 \%$, and histrionics in $12 \%$, followed by obsessive/compulsive personality disorder in $7 \%$. They also showed that significantly more men met criteria for paranoid and narcissistic personality disorder than women, who met criteria for histrionic personality disorder more often than men. Polatin et al (34) in an evaluation of 200 chronic low back pain sufferers, showed that $51 \%$ of patients met criteria for one personality disorder and $30 \%$ met criteria for more than one personality disorder. They also showed that paranoid personality disorder was the most common, present in $33 \%$ of the patients; followed by borderline, present in $15 \%$ of the patients; avoidant, present in $14 \%$ of the patients; and passive/aggressive, present in $12 \%$ of the patients. Vittengl et al (163), in investigating personality characteristics in 125 chronic pain patients and 75 normal controls, examined personality pathology in a subsample of chronic low back pain patients, with 49 patients in one sample and 59 in the second sample before and after treatment with functional rehabilitation. They reported that reductions in personality pathology between pre- and posttreatment assessments were more pronounced for diagnostic interview than dimensional self-report assessments. They showed that in those patients assessed pre- and posttreatment $(\mathrm{N}=56)$ paranoid, obsessive/compulsive, passive/ aggressive, and self-defeating personality disorders decreased significantly from pretreatment. However, this is in contrast to the concept of personality disorder, which is a lifelong and stable condition over a lifetime. Gatchel et al (164), in comparing 152 low back pain patients who returned to work with those who failed to return to work following a functional restoration program, showed that the most common personality disorders found in both groups were paranoid personality disorder, passive/aggressive personality disorder, and borderline personality disorder, with no significant differences between both groups. Manchikanti et al (37) evaluated 100 patients with chronic pain and compared them to control volunteers without history of pain or psychological disorder. This study showed that evaluation for clinical personality patterns for schizoid, avoidant, depressive, dependent, histrionic, narcissistic, anti-social, sadistic, compulsive, negativistic, and masochistic; and for severe personality pathology which included schizotypal pathology, borderline pathology, and paranoid pathology showed a somewhat higher incidence of personality patterns showing features, traits and disorder, as well as severe personality pathology but there were no significant differences in chronic pain patients compared to the healthy participants with negative psychological history and without pain. Surprisingly, compulsive, histrionic, narcissistic, and sadistic patterns were seen in a larger number of subjects in the control group, though not statistically significant.

Most of the early psychological studies on back pain focused on personality and were thought to show that patients with chronic low back pain were neurotic (7). The results of early psychological tests were interpreted as fixed characteristics of the person's psychological makeup. These studies only looked at patients after they had developed chronic pain, but it was assumed that these were preexisting personality traits. Thus, the theory developed that people with certain types of personality would be more likely to develop chronic pain. Unfortunately, the implication was that there was little they or anyone else could do about chronic low back pain in patients with personality disorders (7).

However, subsequent studies showed that these test findings are not fixed and immutable personality traits (7). Main and Waddell (7) noted that, when patients are followed through the acute stage and as they get better, these psychological features develop and then improve with the patient's clinical progress. They further stated that no one has been able to identify any particular personality type that predisposes to back pain. Main and Waddell (7), commenting on the reports from highly specialized clinics showing that $30 \%$ to $50 \%$ of their chronic pain patients may have some type of personality disorder, concluded that these clinics have a high proportion of patients with a history of physical or sexual abuse, alcohol and drug problems and severe personality disorders. They also stated that there are problems with the diagnosis of personality disorders, as the criteria used may give the same diagnosis in about $10 \%$ of the normal population. Thus, it appears that personality studies do not tell us much about the average patient with back pain.

Main and Waddell (7) summarized the relationship of personality disorders, chronic pain, and numerous misconceptions in six dimensions. They specifically described chronic low back pain and felt that it was essential to start with a clean slate. First, back pain is usually not psychogenic. Emotional and psychological disturbances and illness behavior do not tell us anything about the original cause of the pain. Most back pain starts with a physical 
problem in the back, even if it is only the simple backache that we all get at some time. Most emotional and psychological changes occur secondarily to physical pain. Second, it is impossible to divide pain into physical or psychological, organic or nonorganic, real or imaginary. It is wrong to assume that pain is psychological if there are a few or no physical findings. Physical pain and emotional changes are not alternatives and they are two sides of the same coin. Failure to find the physical cause of back pain does not mean that the pain is psychogenic, any more than the presence of emotional changes excludes a treatable physical problem. Third, most ordinary patients with back pain have nothing wrong with their personality. Fourth, patients with chronic back pain are not mentally ill and do not have a primary psychiatric illness, and attempts at a formal psychiatric diagnosis are inappropriate. The terms hysteria and hypochondriasis have been so variously used, misused and abused that medical professions should discard them completely in the context of back pain. Finally, few patients with back pain are malingering. Most of the emotional and psychological changes and illness behavior occurs in the absence of any claims for compensation; and, in most cases, patients cannot help how they react to pain. It is extremely important to realize that emotions are generally outside the conscious control of the person and that most illness behavior is involuntary.

While Main and Waddell (7) so elegantly described misconceptions about personality disorders and their relationship in chronic low back pain, we believe that the same principles apply to almost all chronic pain conditions unless indicated otherwise and patients present with predominantly psychogenic features indicating the diagnosis of chronic pain syndrome or psychogenic pain. Even though Main and Waddell (7) focused on low back pain and discussion about psychogenic pain, their observations apply to all types of pain problems which are predominantly within physical reasons.

\section{PSYCHOGENIC PAIN}

The concept of psychogenic pain has stimulated controversy in the field of pain medicine, not only regarding its prevalence, but indeed its very existence (26). Psychogenic pain essentially is considered within the context that, "since there is nothing wrong with your body, there must be something wrong with you." This may be a question of fact for very few; however, the interpretation is subject to distortion based on specialty, knowledge, bias, and personal philosophy of the physician, as well as a multitude of factors concerning the patient. There is significant argument surrounding the question of psychogenic pain. Some even state that the term psychogenic pain is fundamentally meaningless. Diagnosis of psychogenic pain not only fails to provide a valid organic diagnosis, but also fails to provide validation of patient symptomatology and complaints. Psychogenic pain also implies it is unreal or illusional. Except for a few physicians, adherent to a strong proposition of a psychosocial model without a biomedical component, many physicians in general and interventional pain physicians in particular see diagnosis and branding of a patient with psychogenic pain as not only a great disservice and dismissal of a pathologic condition without proper investigation, but also as dismissal of a patients' pain and suffering. However, psychosocial proponents may argue that failure to adapt the terminology of psychogenic pain may be selfish in that, with a diagnosis of psychogenic pain, one is dismissing the diagnosis of organic pain; thus, no physical or biomedical treatments should be applied.

The concept of psychogenic pain is further weakened by the fact that its diagnostic signs have been challenged (165). Modern technology, including magnetic resonance imaging, computed tomographic axial scanning, neurophysiologic testing, and comprehensive physical examination with psychological evaluation, can identify the cause of low back pain in only $15 \%$ of patients in the absence of disc herniation and neurological deficit (25). With the development of minimally invasive interventional technology, the diagnostic dilemma of chronic low back pain may be untangled, and an organic cause may be identified in approximately $70 \%$ to $85 \%$ of the patients (25). In fact, utilizing precision diagnostic injections, facet joint pain has been diagnosed in $15 \%$ to $45 \%$ of patients with low back pain and $54 \%$ to $60 \%$ of patients with neck pain, discogenic pain in $26 \%$ to $39 \%$, and sacroiliac joint pain in $19 \%$ to $30 \%(166-176)$.

In addition, overall inaccurate or incomplete diagnosis in patients referred to pain treatment centers has been described as ranging from $40 \%$ to $67 \%$; and the incidence of psychogenic pain has been shown to be present only in 1 of 3,000 patients, with the presence of organic origin of pain mistakenly branded as psychosomatic in $98 \%$ of the cases $(177,178)$. Thus, strong arguments may be made on both sides as to the presence or absence of psychogenic pain. Similar to the interventional pain physicians who benefit from organic diagnosis, behavioralists benefit from the diagnosis of psychogenic pain. An additional dimension of psychogenic pain is the lack of compensation or disability income, and the basis for denial of care because psychogenic pain is considered not to be a real problem. 
Psychogenic pain should not be confused with factitious illness and malingering. Malingering, the use of willful deception for a covert purpose, is presumed to be extremely low. Fishbain et al, evaluating the chronic pain disability exaggeration/malingering and submaximal effort research, concluded that there were serious methodological flaws in the available literature which precluded them from concluding from the data, which suggested that malingering is present variably in from $1 \%$ to $10 \%$ of patients. However, malingering, factitious illness, substance abuse, substance dependency, and psychopathology can coexist, not only with organic pain, but also with psychogenic pain, which is presumably seen in a small percentage of patients.

In summary, psychogenic pain is mainly an illusion. Main and Waddell (7) stated that back pain arises from a physical problem in the back and is usually not psychogenic; physicians are unable to divide back pain into physical or psychologic types of pain; and most patients with back pain are no different from patients who are not suffering with pain; they are not malingering and also do not have a psychiatric disorder. While there are no such strong statements available for all types of chronic pain, Hendler and Kolodny (178) have shown that psychogenic pain is seen in only 1 in 3,000 patients. In addition, they were able to find a physical reason in $98 \%$ of the patients who were labeled as psychosomatic.

\section{IMPACT OF PSYCHOLOGIC DISORDERS}

Chronic pain disability is a complex psychosocial economic phenomenon (98). In fact, Waddell et al (179) stated that, among patients approved for disability, only half of cases of chronic low back pain can be attributed to physical impairment. In the earlier literature, most cases of low back pain are classified as "soft-tissue injuries" because they are ill defined, without physical, neurological, or radiologic findings. In addition, clinical features and imaging or neurophysiologic studies do not permit accurate diagnosis of the causation of spinal pain in $85 \%$ of patients in the absence of disc herniation and neurological deficit $(25,166-185)$. It has also been shown that sacroiliac joint pain may be resistant to identification by historical and physical examination data (185). Manchikanti et al (166) rationalized, with diagnostic neural blockade or precision diagnostic interventional technology, that diagnosis in chronic low back pain in $85 \%$ of patients is not permitted; but, with interventional technology, this proportion of patients who cannot be given a definite diagnosis may be reduced to $32 \%$ or even to $19 \%$. Thus, in most of the studies performed prior to development of precision diagnostic technology and before recent publications, the conclusions derived in the past are considered only as assumptions. To nonbelievers in precision diagnostic interventional technology, of course, psychopathology continues to be a major issue. The role of psychological factors in provocative discography and facet joint pain also has been proven to be nonexistent $(38,39)$. Even then, it is agreed that psychological and/or emotional factors may contribute to determine how patients respond to the treatment. However, this does not necessarily mean that such patients are malingerers who are faking their level of disability or that they are suffering with psychogenic pain. Thus far, there is no convincing evidence that chronic low back pain develops secondary to psychopathology and that the response to treatment is hindered significantly based on psychopathology. In addition, it is extremely important to separate psychopathology, which includes depression, anxiety, somatization and personality disorders and other psychiatric conditions, from psychosocial factors, which include gender, high-risk jobs, job dissatisfaction, interpersonal conflicts, role conflict and repetitive work, and lack of interest in the job. Psychosocial factors have been shown to have a significant correlation to chronic low back pain, at least as possible or occasionally probable risk factors.

As shown above, even though physical factors have been found to predict outcome in lumbar surgery (186-188), there has been a growing body of evidence indicating that psychosocial factors also have a significant influence on the outcome of lumbar surgery (186). Results of research have shown that the MMPI, especially elevations on the HS and HY subscales, can predict poor outcome of back surgery (189-192). However, there are serious concerns about the psychometric soundness of MMPI evaluation and its clinical utility for the specific population of patients with back pain (186, 193-195). The MMPI has been criticized in that it may not measure immutable personality traits, as it is believed; but that it largely assesses mood states (196). Personality disorders are lifelong, pervasive stable traits; and the clinical utility of the MMPI is very narrow, as it is an extremely time-consuming, expensive test with a low rate of satisfactory completion by patients (186). However, the association between the surgical outcome, depression, generalized anxiety disorder, somatization disorder, schizophrenia, and various personality disorders has not been explored. Most of the research was concentrating on a combination of multiple factors. Trief et al (186), utilizing the Spielberger Trait Anxiety Inventory, Zung Depression Scale, MSPQ, and Hostility Scale, attempted to evaluate the psychological predictors of sur- 
gery outcome in a prospective evaluation. The results showed that failure to return to work was predicted by presurgical anxiety and depression; failure to report improvement in pain, and failure to report improved functional abilities were predicted by presurgical somatic anxiety and depression. They also showed that a strong predictor is a combination of the Zung Depression Scale and MSPQ, known as the Distress and Risk Assessment Method (DRAM). They concluded that screening for presurgical distress is likely to identify those patients at risk for poor outcome, and they recommended that presurgical psychological treatment and its relation to outcomes should be studied. Once again, this is an extremely cumbersome evaluation prior to surgical interventions, more so prior to interventional procedures. At the present time, there are no studies showing the relationship of psychological predictors to the outcome of interventional procedures, excluding surgical interventions such as interventions on the disc, intrathecal infusion systems, and spinal cord stimulation. The influence of somatization was studied in relation to provocative discography; however, the results were criticized and disproven in another study (38). Similar to surgical outcomes, studies in interventional pain medicine evaluate whether preprocedure psychological assessment and treatment will improve outcomes.

\section{TREATMENT}

While there are no data available in the medical literature at all with regards to the treatment of personality disorders, there are also no data available with regards to the treatment of somatization disorder and anxiety disorders in chronic pain and its influences. However, when it comes to depression, it is somewhat clear from the modest number of studies conducted to date that the treatment of depression, in the context of general medical conditions, may well improve the prognosis of both the depression, as well as the general medical condition (5). There is proven efficacy for antidepressant medication, psychotherapy, or a combination of both for the treatment of any depression; and, particularly, for the more chronic presentations (197). The therapeutic approach described for patients with general medical conditions, including chronic pain, with depression is to treat with a fully tolerated dose of antidepressant medication for 4 weeks and, if there has been a reduction in symptoms of at least $20 \%$ from baseline, to continue for an additional 4 weeks (5). A total of 12 to 16 weeks of therapy is required to assess maximal symptomatic and functional benefit from a single treatment trial.

To avoid the deleterious effects of depression on the out- come of surgery, it has been recommended to treat and remove the depression, if at all possible. The advantage of this technique is that, if the pain symptoms persist at the same level of severity, at least the presence of depression can be excluded as a cause of the symptoms (5). However, it is also stated that to refuse surgery to individuals who have the additional disorder of depression would also be unwise and unfair (5). Thus, the decision to operate cannot depend solely on the presence or degree of psychopathologic disorder in patients with chronic pain. Such patients may have slight or severe depression, and the chronic pain may or may not be attributable to structural disease that is correctable with surgical methods (5). The best recommendation is to screen for emotional distress and aggressively treat psychopathologic disorder when present, and to reduce stressful environmental factors, including marital and occupational, physical, and legal issues before surgery. However, it would not be wise to delay surgery to uncover unsuspected psychopathologic disease. In addition, Rush et al (5) outlined measures to be undertaken to optimize postoperative recovery in patients with severe psychopathological disorder, but in need of surgery. These include family support, which improves the likelihood of better outcomes in the treatment of both depression and general medical conditions. In fact, Penninx et al (78) showed that depressed patients have far fewer close friends and much less social support than non-depressed patients, which reinforces isolation and depression. Thus, engaging the family and the support systems for the patient before surgery and augmenting or providing further support after surgery probably improves outcome.

The same philosophy may be applied to interventional pain procedures, presuming that an interventional pain procedure is indicated for a structural disorder accounting for the pain symptoms, and that the psychopathologic condition does not fully account for the symptomatology when it is present.

Thus, to refuse interventional pain procedures for individuals with disorders of psychopathology which are present in addition to physical disorder is not only unwise, but also unfair.

\section{CONCLUSION}

Patients with chronic pain frequently have psychopathology - most often, depressive disorders, anxiety disorders, somatization disorders, drug dependence and occasionally personality disorders. Chronic pain should not be dis- 
counted or ignored because of its association with psychopathology. Similarly, psychopathology should not be discounted or ignored because of an association with chronic pain. It is important to recognize that not all patients with chronic pain suffer with psychopathology. However, it is also equally important to recognize that psychopathology, when present, influences pain and may in turn, be influenced by the level of pain. It is essential to diagnose the psychopathology prior to embarking on interventional procedures, to try to maximally treat psychopathology to the best of one's ability and to reduce the chronic pain to some extent if psychopathology is a confounding factor. If a patient is an optimal candidate for interventional techniques, one should follow the established algorithm for treatment of psychopathology in conjunction with following an algorithmic approach to treatment of chronic pain.

\section{REFERENCES}

1. Magid CS. Pain, suffering, and meaning. JAMA 2000; 283:111.

2. Sullivan MD. Assessment of psychiatric disorders. In Turk DC, Melzack R (eds). Handbook of Pain Assessment, Second Edition, Guilford Press, New York, 2001, pp 275-291.

3. Dersh J, Gatchel RJ, Polatin P. Chronic spinal disorders and psychopathology: Research findings and theoretical considerations. Spine 2001; 1:88-94.

4. Manchikanti L, Pampati V, Fellows B et al. Characteristics of chronic low back pain in patients in an interventional pain management setting: A prospective evaluation. Pain Physician 2001; 4:131-142.

5. Rush AJ, Polatin P, Gatchel RJ. Depression and chronic low back pain. Spine 2000; 25:2566-2571.

6. Long DM, Debba MB, Torgerson WS et al. Persistent back pain and sciatica in the United States: Patient characteristics. J Spinal Disord 1996; 9:40-58.

7. Main CJ, Waddell G. Psychologic distress. In Waddell G (ed). The Back Pain Revolution. Churchill Livingstone, Philadelphia, 1998, pp 173-186.

8. Gatchel RJ, Turk DC. Preface. In Gatchel RJ, Turk DC (eds). Psychosocial Factors in Pain. The Guilford Press. New York, 1999, pp XIII - XIV.

9. Gatchel RJ. Perspectives on pain: A historical review. In Gatchel RJ, Turk DC (eds). Psychosocial Factors in Pain. The Guilford Press. New York, 1999, pp 317.

10. Heavner JE. Newer concepts in pain mechanisms. Curr Rev Pain 1999; 3:453-457.

11. Grachev ID, Fredrickson BE, Apkarian AV. Abnormal brain chemistry in chronic back pain: An in vivo proton magnetic resonance spectroscopy study. Pain 2000 ; 89:7-18.
12. Sullivan MD. Finding pain between minds and bodies. Clin J Pain 2001; 17:146-156.

13. Gatchel RJ, Epkar J. Psychological predictors of chronic pain and response to treatment. In Gatchel RJ, Turk DC (eds). Psychosocial Factors in Pain. The Guilford Press. New York, 1999, pp 412-434.

14. Robinson ME, Riley III JL. The role of emotion in pain. In Gatchel RJ, Turk DC (eds). Psychosocial Factors in Pain. The Guilford Press, New York, 1999, pp 74-88.

15. Melzack R, Casey KL. Sensory, motivational, and central control determinants of pain: A new conceptual model. In Kerschal D (ed). The Skin Senses. Charles C. Thomas, Springfield, 1968.

16. Melzack R, Wall PD. Pain mechanisms: A new theory. Science 1965; 50:971-979.

17. Fordyce WE. Pain and suffering: A reappraisal. $A m$ Pyschol 1988; 43:276-283.

18. Fordyce WE, Bigos S, Battie Met al. MMPI Scale 3 as a predictor of back injury report: What does it tell? Clin J Pain 1992; 8:222-226.

19. Fordyce WE, Lansky D, Calsyn DA et al. Pain measurement and pain behavior. Pain 1984; 18:53-65.

20. Fordyce WE, Roberts AH, Sternbach RA. The behavioral management of chronic pain: A response to critics. Pain 1985; 22:113-125.

21. Bonica JJ. The Management of Pain. Second edition. Lea \& Febiger. Philadelphia, 1990.

22. Regier DA, Narrow WE, Rae DS et al. The de facto mental and addictive disorders service system. Epidemiologic Catchment Area prospective 1-year prevalence rates of disorders and services. Arch Gen Psychiatry 1993; 50:85-94.

23. Narrow WE. One-year prevalence of mental disorders, excluding substance use disorders, in the U.S.: NIMH ECA prospective data. Population estimates based on U.S. Census estimated residential population age 18 and over on July 1, 1998.

24. Murray CJ, Lopez AD (eds). The Global Burden of Disease: A Comprehensive Assessment of Mortality and Disability from Diseases, Injuries, and Risk Factors in 1990 and Projected to 2020. Cambridge, MA, Harvard School of Public Health on behalf of the World Health Organization and the World Bank, Harvard University Press, 1996. http://www.who.int/msa/mnh/ ems/dalys/intro.htm

25. Manchikanti L, Singh V, Kloth D et al. Interventional techniques in the management of chronic pain: Part 2.0. Pain Physician 2001; 4:24-96.

26. CovingtonEC. Psychogenic pain-What it means, why it does not exist, and how to diagnose it. Pain Med 2000; 1:287-294.

27. Narrow WE, Rae DS, Regier DA. NIMH epidemiology note: Prevalence of anxiety disorders. One-year prevalence best estimates calculated from ECA and NCS data. Population estimates based on U.S. Cen- 
sus estimated residential population age 18 to 54 on July 1, 1998.

28. Regier DA, Rae DS, Narrow WE et al. Prevalence of anxiety disorders and their comorbidity with mood and addictive disorders. Br J Psychiatry(Suppl.) 1998; 34:24-28.

29. Wonderlich SA, Mitchell JE. Eating disorders and comorbidity: Empirical, conceptual, and clinical implications. Psychopharmacol Bull 1997; 33:381-390.

30. Magni G, Caldieron C, Rigatti-Luchini S et al. Chronic musculoskeletal pain and depressive symptoms in the general population: An analysis of the $1{ }^{\text {st }}$ National Health and Nutrition Examination Survey data. Pain 1990; 43:299-307.

31. Dworkin RH, Gitlin MJ. Clinical aspects of depression in chronic pain patients. Clin J Pain 1991; 7:7994.

32. Fishbain DA, Cutler R, Rosomoff HL et al. Chronic pain associated depression: Antecedent or consequence of chronic pain? A review. Clin J Pain 1997; 13:116137.

33. Von Korff M, Simon G. The relationship between pain and depression. Br J Psychiatry(suppl.) 1996;30:101108.

34. Polatin PB, Kinney RK, Gatchel RJ et al. Psychiatric illness and chronic low back pain: The mind and the spine -which goes first? Spine 1993; 18:66-71.

35. Mannion A, Dolan P, Adams M. Psychological questionnaires: Do "abnormal" scores precede or follow first-time low back pain? Spine 1996; 212603-2611.

36. Biering-Sorenson F. Physical measurements as risk indicators for low back trouble over a one-year period. Spine 1984; 9:106-118.

37. Manchikanti L, Fellows B, Pampati VS et al. Comparison of psychological status of chronic pain patients and the general population. Pain Physician 2002; 5: 40-48

38. Manchikanti L, Singh V, Pampati VS et al. Provocative discography in low back pain patients with or without somatization disorder: A randomized, prospective evaluation. Pain Physician 2001; 4:227-239.

39. Manchikanti L, Pampati VS, Fellows B et al. Influence of psychological factors on the ability to diagnose chronic low back pain of facet joint origin. Pain Physician 2001; 4:349-357.

40. Aronoff GM, Tota-Faucette M, Phillips L et al. Are pain disorder and somatization disorder valid diagnostic entities? Curr Rev Pain 2000; 4:309-312.

41. Fink P, Sorensen L, Engberg M et al. Somatization in primary care. Prevalence, health care utilization, and general practitioner recognition. Psychosomatics 1999; 40:330-338.

42. Üstün TB, Sartoius N. Mental illness in general health care: An international study. Geneva, World Health Organization, 1995

43. Fink P, Jensen J, Borgquist Let al. Psychiatric morbidity in primary public health care. A Nordic multicenter investigation. Part I: Method and prevalence of psychiatric morbidity. Acta Psychiatr Scand 1995; 92:409-418.

44. Fishbain DA. Somatization, secondary gain, and chronic pain: Is there a relationship? Curr Rev Pain 1998; 6:101-108.

45. Sullivan M, Katon W. Somatization: The path between distress and somatic symptoms. Am Pain SocJ 1993; 2:141-149.

46. Kellner R, Sheffield BR. The one-week prevalence of symptoms in neurotic patients and normals. Am JPsychiatry 1973; 130:102-105.

47. Aronoff GM. Psychodynamics and psychotherapy of the chronic pain syndrome. In Aronoff GM (ed). Evaluation and Treatment of Chronic Pain, ThirdEdition. Williams and Wilkins, Philadelphia, 1999, pp 83-290.

48. Ford CV. The somatizing disorders. Psychosomatics 1986; 27:327-337.

49. Sikorski JM, Stampfer HG, Cole RM et al. Psychological aspects of chronic low back pain. Aust NZJ Surg 1996; 66:294-297.

50. Weisberg JN, Keefe FJ. Personality disorders in the chronic pain population: Basic concepts, empirical findings, and clinical implications. Pain Forum 1997; 6:1-9.

51. Engel GL. "Psychogenic" pain and the pain-prone patient. Am J Med 1959; 26:899-918.

52. Hanvik LJ. MMPI profiles in patients with low back pain. J Consult Psychol 1951;15:350-353.

53. Sternbach RA, Wolf SR, Murphy RW et al. Aspects of chronic low back pain. Psychosomatics 1973; 14:5256.

54. Szasz TS. Pain and pleasure: A study of bodily feelings. Tavistock, London, 1957.

55. Woodforde JM, Merskey H. Personality traits of patients with chronic pain. J Psychosom Res 1972; 16:167-172.

56. Coste J, Delecoeuillerie G, Cohen de Lara A et al. Clinical course and prognostic factors in acute low back pain: An inception cohort study in primary care practice. BMJ 1994; 308:577-580.

57. Greenough CG, Fraser RD. The effects of compensation on recovery from low-back injury. Spine 1989; 14:947-955.

58. Greenough CG, Fraser RD. Comparison of eight psychometric instruments in unselected patients with back pain. Spine 1991; 16:1068-1074.

59. Williams MM, Grant RN, Main CJ. The distress and risk assessment method (DRAM) as a predictor of outcome in chronically disabled workers attending a physical rehabilitation program. Proceedings of the International Society for the Study of the Lumbar Spine. Hensinki, Finland, June 18-21, 1995.

60. Burton AK, Tillotson KM, Main CJ et al. Psychoso- 
cial predictors of outcome in acute and subchronic low back trouble. Spine 1995;20:722-728.

61. Gatchel RJ, Polatin PB, Mayer TG. The dominant role of psychosocial risk factors in the development of chronic low back pain disability. Spine 1995;20:27022709.

62. Hasenbring M, Marienfeld G, Kuhlendahl D et al. Risk factors of chronicity in lumbar disc patients. Spine 1994; 19:2759-2765.

63. Main CJ, Wood PLR, Hollis S et al. The distress and risk assessment method: A simple patient classification to identify distress and evaluate the risk of poor outcome. Spine 1992; 17:42-52.

64. Waddell G, Newton M, Henderson I et al. A FearAvoidance Beliefs Questionnaire (FABQ) and the role of fear-avoidance beliefs in chronic low back pain and disability. Pain 1993; 52:157-168.

65. Bigos SJ, Battie MC, Spengler DM et al. A prospective study of work perceptions and psychosocial factors affecting the report of back injury. Spine 1991; 16:1-6.

66. Volinn E, Spratt KF, Magnusson M et al. The Boeing prospective study and beyond. Spine 2001; 26:16131622.

67. Magora A. Investigation of the relation between low back pain and occupation: V: Psychological aspects. Scand J Rehabil Med 1973;5:191-196.

68. Svensson H-O, Andersson GBJ. The relationship of low-back pain, work history, work environment and stress. Spine 1989; 14:517-522.

69. Hoogendoorn WE, van Poppel NM, Bongers PM. Systematic review of psychosocial factors at work and private life as risk factors for back pain. Spine 2000; 25:2114-2125.

70. Hansen FR, Biering-Sorensen F, Schroll M. What came first: Low-back pain or MMPI changes? Proceedings of the International Society for the Study of the Lumbar Spine. Helsinki, Finland, June 18-21, 1995.

71. Gatchel RJ. Psychological disorders and chronic pain: Cause-and-effect relationships. InPsychological Approaches to Pain Management: A practitioners handbook. Gatchel RJ, Turk DC (eds). Guilford Publications, New York, 1996:33-52.

72. Hensing G, Spak F. Psychiatric disorders as a factor in sick leave due to other diagnoses: A general population-based study. Br J Psychiat 1998;172:250-256.

73. Holzberg AD, Robinson ME, Geisser ME. The effects of depression and chronic pain on psychosocial and physical functioning. Cliin J Pain 1996; 12:118-125.

74. Burchiel KJ, Anderson VC, Wilson BJ. Prognostic factors of spinal cord stimulation for chronic back and leg pain. Neurosurgery 1995;36;1101-1111.

75. Burns JW, Johnson BJ, Mahoney N et al. Cognitive and physical capacity process variables predict longterm outcome after treatment of chronic pain. JClin Cons Psycho 1998; 66:434-439.
76. Gatchel RJ, Polatin PB, Mayer TB et al. Psychopathology and the rehabilitation of patients with chronic low back pain disability. Arch Phys Med Rehab 1994; 75:666-670.

77. Kremer E, Atkinson JH, Fagnelzi RN. Measurement of pain: Patient preference does not confound pain measurement. Pain 1981; 51:281-287.

78. Cornwal A, Doncleri DC. The effect of experimentally induced anxiety on the experience of pressure pain. Pain 1988; 35:105-113.

79. Katon WJ. The impact of major depression on chronic medical illness. Gen Hosp Psychiat 1996; 18:215-219.

80. Barksy AJ, Klerman GL. Overview: Hypochondriasis, bodily complaints, and somatic styles. Am J Psychiat 1983; 140:273-283.

81. Heliovaara M. Risk factors for low back pain and sciatica. Ann Med 1989; 21:257-264.

82. Magni G. Chronic low-back pain and depression: An epidemiologic survey. Acta Psychiatr Scand 1984; 70:614-617.

83. Biering-Sorensen F, Thomsen C. Medical, social, and occupational history as risk indicators for low back trouble in a general population. Spine 1986;11:720725.

84. Croft P, Ferry S, Papageorgious A et al. Depression and back pain in the general population: A prospective study from the South Manchester cohort. Proceedings of the International Society for the Study of the Lumbar Spine. Helsinki, Finland, June 18-21, 1995.

85. Klerman GL, Weissman MM. Increasing rates of depression. J Am Med Inform Assoc 1989; 261:22292235.

86. Diagnostic and Statistical Manual for Mental Disorders. Fourth Edition (DSM-IV). American Psychiatric Association. Washington, 1994.

87. Turk DC, Salovey P. Chronic pain as a variant of depressive disease: A critical reappraisal. JNervMent Dis 1984; 172:398-404.

88. Banks SM, Kerns RD. Explaining high rates of depression in chronic pain: A diathesis-stress framework. Psychol Bull 1996;119:95-110.

89. Romano JM, Turner JA. Chronic pain and depression: Does the evidence support a relationship? Psychol Bull 1985; 97:18-34.

90. Breslau N, Davis GC. Migraine, major depression and panic disorder: A prospective epidemiologic study of young adults. Cephalgia 1992; 12:85-90.

91. Breslau N, Merikangas K, Bowden CL. Comorbidity of migraine and major affective disorders. Neurology 1994; 44:S17-S22.

92. Von Korff M, Le Resche L, Dworking SF. First onset of common pain symptoms: A prospective study of depression as a risk factor. Pain 1993; 55:251-258.

93. Moldofsky H, Chester WJ. Pain and mood patterns in patients with rheumatoid arthritis: A prospective study. 
Psychosomatic Medicine 1970;32:309-318.

94. Breslau N, Davis GC, Schultz LR et al. Migraine and major depression: A longitudinal study. Headache 1994; 12:387-393.

95. Leino P, Magni G. Depressive and distress symptoms as predictors of low back pain, neck-shoulder pain, and other musculoskeletal morbidity: A 10-year followup of metal industry employees. Pain 1993; 53:8994.

96. Brown GK. A causal analysis of chronic pain and depression. J Abnorm Psychol 1990;99:127-137.

97. Magni G, Merskey H et al. Prospective study on the relationship between depressive symptoms and chronic musculoskeletal pain. Pain 1994;56:289-297.

98. Barsky AJ, Goodson, DJ, Lane RS. The amplification of somatic symptoms. Psychosomatic Medicine1988; 50:510-519.

99. Dworkin SF, Wilson L, Masson DL. Somatizing as a risk factor for chronic pain. InPsychologicalvulnerability to chronic pain. RC Grzesiak, DC Ciccone (eds). Springer, New York, 1994.

100. Kramlinger KG, Swanson DW, Maruta T. Are patients with chronic pain depressed? Am J Psychiatry 1983; 140:747-749.

101. Magni G. On the relationship between chronic pain and depression when there is no organic lesion. Pain 1987; 31:1-21.

102. Wallis BJ, Lord SM, Bogduk N. Resolution of psychological distress of whiplash patients following treatment by radiofrequency neurotomy: A randomized, double-blind, placebo-controlled trial. Pain 1997; 73:15-22.

103. Manchikanti L, Pampati V, Bakhit C et al. Effectiveness of lumbar facet joint nerve blocks in chronic low back pain: A randomized clinical trial. Pain Physician 2001; 4:101-117.

104. Manchikanti L, Pampati V, Fellows B et al. Role of one day epidural adhesiolysis in management of chronic low back pain: A randomized clinical trial. Pain Physician 2001; 4:153-166.

105. Penninx BW, Leveille S, Ferrucci L et al. Exploring the effect of depression on physical disability: Longitudinal evidence from the established populations for epidemiologic studies of the elderly. Am JPublic Health 1999; 89:1346-1352.

106. Krishnan K, France R, Houpt J. Chronic low back pain and depression. Psychosomatics 1985; 26:299-302.

107. Flor H, Turk DC, Birbaumer N. Assessment of stressrelated psychophysiological reactions in chronic back pain patients. J Cons Clin Psychol 1985; 53:354364.

108. Weisberg JN, Gorin A, Drozd J et al. Therelationship between depression and psychophysiological reactivity in chronic pain patients. Poster presented at the Eighth World Congress on Pain, Vancouver, BC, Canada, August, 1996.
109. Waddell G, Bircher M, Finlayson D et al. Symptoms and sings: Physical disease or illness behavior? Brit Med J 1984; 289:739-741.

110. Robins LN, Regier DA (eds). Psychiatric Disorders in America: The Epidemiologic Catchment Area Study. The Free Press, New York, 1991.

111. Bourdon KH, Boyd JH, Rae DS et al. Gender differences in phobias: Results of the ECA community survey. J Anx Disord 1998; 2:227-241.

112. Davidson JR. Trauma: The impact of post-traumatic stress disorder. J Psychopharmacol (2Suppl 1). 2000; 14:S5-S12.

113. Asmundson GJ, Jacobson SJ, Allerdings MD et al Social phobia in disabled workers with chronic musculoskeletal pain. Behav Res Ther 1996; 34:939-943.

114. Atkinson JH, Slater MA, Patterson TL et al. Prevalence, onset, and risk of psychiatric disorders in men with chronic low back pain: A controlled study. Pain 1991; 45:111-121.

115. Asmundson GJ, Norton GR, Allerdings MD. Fear and avoidance in dysfunctional chronic back pain patients. Pain 1997; 69:231-236.

116. Croft PR, Papgeorgiou AC, Ferry S et al. Psychologic distress and low back pain. Evidence from a prospective study in the general population. Spine 1995; 20:2731-2737.

117. Main CJ. The modified somatic perception questionnaire. J Psychosom Res 1983; 27:503-514.

118. Lipowski ZJ. Somatization and depression. Psychosomatics 1990; 31:13-21.

119. Aronoff GM. Psychiatric aspects of nonmalignant chronic pain: A new nosology. In Aronoff GM (ed). Evaluation and Treatment of Chronic Pain, ThirdEdition. Williams and Wilkins, Philadelphia, 1999; pp 291-300.

120. Epstein R, Quill T, McWhinney I. Somatization reconsidered. Arch Intern Med 1999; 59:215.

121. Sifineos PE. The prevalence of "alexithymic" characteristics in psychosomatic patients. Psychother Psychosom 1973;22:255-262.

122. Kroenke K, Mangelsdorff A. Common symptoms in ambulatory care: Incidence, evaluation, therapy, and outcome. Am J Med 1989; 86:262-266.

123. Pilowsky I, Spence ND. Patterns of illness behavior in patients with intractable pain. JPsychosom Res 1975; 19:279-287.

124. Bacon NM, Bacon SF, Atkinson JH et al. Somatization symptoms in chronic low back pain patients. Psychosom Med 1994;56:118-127.

125. Fishbain DA, Cutler R, Rosomoff HL et al. Chronic pain disability exaggeration /malingering and submaximal effort research. Clin J Pain 1999; 15:244274.

126. Korbon GA, DeGood DE, Schroeder ME et al. The development of a somatic implication rating scale for low back pain. Spine 1987; 12:787-791. 
127. Cassisi JE, Sypert GW, Lagara L et al. Pain disability and psychosocial function in CLBP subgroups: Myofascial versus herniated disc. Neurosurgery1993; 33:379-385

128. Block A, Vanharanta H, Ohnmeiss D et al. Discographic pain report: Influence of psychological factors. Spine 1996; 1:334-338.

129. Manchikanti L. Epidemiology of low back pain. Pain Physician 2000; 3:167-192.

130. Schmidt AJM, Gierlings EH, Madelon LP. Environmental and interoceptive influences on chronic low back pain behavior. Pain 1989; 38:137-143.

131. Wiltse LL, Rocchio PD. Preoperative psychological tests as predictors of success of chemonucleolysis in the treatment of low back syndrome. J Bone Joint Surg [Am] 1975; 57:478-483.

132. Bradley LA, Prokop CV. Margolis R et al. Multivariate analysis of the MMPI profiles of low back pain patients. J Psychosom Med 1978; 1:253-272.

133. Graham JR. The MMPI-2: Assessing personality and psychopathology. Oxford University Press, New York, 1990.

134. Carragee EJ, Tanner CM, Khurana S et al. The rates of false-positive lumbar discography in select patients without low back symptoms. Spine 2000; 25:13731381.

135. Manchikanti L, Pampati VS, Damron K et al. Prevalence of opioid abuse in interventional pain medicine practice settings: A randomized clinical evaluation. Pain Physician 2001;4:358-365.

136. Johnson P. The Birth of the Modern World Society. Harper Collins, New York, 1991; p 768.

137. Jamison R, Raymond S, Slawsby E et al. Opioid therapy for chronic noncancer back pain. Spine 1998; 23:2591-2600.

138. Rathmell JP, Jamison RN. Opioid therapy for chronic noncancer pain. Curr Opin Anaesthesiol 1996; 9:436442.

139. Joranson DE. Federal and state regulations of opioids. J Pain Symptom Manage 1990;5:333-336.

140. Turk DC, Okifuji A. What factors affect physicians' decisions to prescribe opioids for chronic noncancer pain patients. Clin J Pain 1997; 13:330-336.

141. Flor H, Fydrich T, Turk DC. Efficacy of multidisciplinary pain treatment centers: A meta-analytic review. Pain 1992; 49:221-230.

142. Manchikanti L, Pampati V, Fellows B et al. Characteristics of chronic low back pain in patients in an interventional pain management setting: A prospective evaluation. Pain 2001; 4:131-142.

143. Groer J, Brodsky M. The incidence of illicit drug use in the United States 1961-1989. Br J Addict 1992; 87:1345.

144. Regier DA, Meyers JK, Dramer et al. The NIMH epidemiologic catchment area program. Arch Gen Psychiatry 1984; $41: 934$.
145. Fishbain DA, RosomoffHL, Rosomoff RS. Drug abuse, dependence, and addiction in chronic pain patients. Clin J Pain 1992; 8:77.

146. Quang-Cantagrel ND, Wallace MS, Magnuson SK. Opioid substitution to improve the effectiveness of chronic noncancer pain control: A chart review. Anesth Analg 2000; 90:933-937.

147. Moulin DE, Lezzi A, Amireh R et al. Randomized trial of oral morphine for chronic non-cancer pain. $J$ Pain Symptom Manage 1992; 7:69-77.

148. Jadad AR, Carroll D, Glynn CJ et al. Morphine responsiveness of chronic pain: Double-blind randomized crossover study with patient-controlled analgesia. Lancet 1992; 339:1367-1371.

149. McNairy SL, Maruta T, Ivnik RJ et al. Prescription medication dependence and neuropsychologic function. Pain 1984; 18:169-177.

150. Fordyce WE. Behavioral Methods for Chronic Pain and Illness. Mosby, St. Louis, 1976.

151. Maruta T, Swanson DW, Finlayson RE. Drug abuse and dependency in patients with chronic pain. Mayo Clin Proc 1979; 54:241-244.

152. Maruta T, Swanson DW. Problems with the use of oxycodone compound in patients with chronic pain. Pain 1981; 11:389-396.

153. Schofferman J. Long-term use of opioid analgesics for the treatment of chronic pain of nonmalignant origin. J Pain Symptom Manage 1993;8:279-288.

154. Turner JA, Calsyn DA, Fordyce WE et al. Drug utilization pattern in chronic pain patients. Pain 1982; 12:357-363.

155. Coccaro EF, Silverman JM, Klar HM et al. Familial correlates of reduced central serotonergic system function in patients with personality disorders. Arch Gen Psychiatry 1994; 51:318-324.

156. Weisberg JN, Keefe FJ. Personality, individual differences and psychopathology in chronic pain. In Gatchel RJ, Turk DC (eds). Psychosocial Factors in Pain. The Guilford Press, New York, 1999, pp 56-73.

157. Engel GL. The need for a new medical model: A challenge for biomedicine. Science 1977; 196:129-136.

158. Flor H, Turk DC. Etiological theories and treatments for chronic back pain: I. Somatic models and interventions. Pain 1984; 19:105-121.

159. Turk DC, Flor H. Etiological theories and treatment for chronic back pain: II. Psychological models and interventions. Pain 1984; 19:209-233.

160. Gatchel RJ, Garofalo JP, Ellis E et al. Major psychological disorders in acute and chronic TMD: An initial examination. J Am Dent Assoc 1996; 127:13651374.

161. Large RG. DSM-III Diagnosis in chronic pain- confusion or clarity? J Nerv Ment Dis 1986; 174:295-302. Fishbain DA, Goldberg M, Meagher BR et al. Male and female chronic pain patients categorized by DSMIII psychiatric diagnostic criteria. Pain 1986; 26:181- 
197.

163. Vittengl JR, Clark LA, Owen-Salters E et al. Diagnostic change and personality stability following functional restoration treatment in a chronic low back pain patient sample. Assessment 1999; 6:79-92.

164. Gatchel RJ, Polatin PB, Mayer TG et al. Psychopathology and the rehabilitation of patients with chronic low back pain. Arch Phys Med Rehabil 1994;75:666670 .

165. Gould R, Miller BL, Goldberg MA et al. The validity of hysterical signs and symptoms. JNerv Ment Dis 1986; 174:593-597.

166. Manchikanti L, Singh V, Pampati V et al. Evaluation of the relative contributions of various structures in chronic low back pain. Pain Physician 2001;4:308316.

167. Schwarzer AC, Aprill CN, Derby R et al. The prevalence and clinical features of internal disc disruption in patients with chronic low back pain. Spine 1995; 20:1878-1883.

168. Schwarzer AC, Aprill CN, Derby R et al. Clinical features of patients with pain stemming from the lumbar zygapophysial joints. Is the lumbar facet syndrome a clinical entity? Spine 1994; 19:1132-1137.

169. Schwarzer AC, Wang S, Bogduk Net al. Prevalence and clinical features of lumbar zygapophysial joint pain: A study in an Australian population with chronic low back pain. Am Rheum Dis 1995; 54:100-106.

170. Manchikanti L, Pampati VS, Fellows B et al. Prevalence of lumbar facet joint pain in chronic low back pain. Pain Physician 1999; 2:59-64.

171. Manchikanti L, Pampati VS, Bakhit CE et al. The diagnostic validity and therapeutic value of lumbar facet joint nerve blocks with or without adjuvant agents. Cur Rev Pain 2000; 4:337-344.

172. Manchikanti L, Pampati VS, Fellows B et al. The inability of the clinical picture to characterize pain from facet joints. Pain Physician 2000; 3:158-166.

173. Barnsley L, Lord SM, Wallis BJ et al. The prevalence of chronic cervical zygapophyseal joint pain after whiplash. Spine 1995; 20:20-26.

174. Lord SM, Barnsley L, Wallis BJ et al. Chronic cervical zygapophysial joint pain with whiplash: A placebocontrolled prevalence study. Spine 1996;21:17371745.

175. Schwarzer AC, Aprill CN, Bogduk M. The sacroiliac joint in chronic low back pain. Spine 1995; 20:31-37.

176. Maigne JY, Aivakiklis A, Pfefer F: Results of sacroiliac joint double block and value of sacroiliac pain provocation test in 54 patients with low back pain. Spine 1996; 21:1889-1892.

177. Hendler NH, Bergson C, Morrison C. Overlooked physical diagnoses in chronic pain patients involved in litigation. Part 2. Psychosomatics 1996;37:509-517.

178. Hendler NH, Kolodny AL. Using medication wisely in chronic pain. Patient Care 1992; May 15:125.
179. Waddell G, Main CJ, Morris EW et al. Chronic low back pain, psychologic distress, and illness behavior. Spine 1984; 9:209-213.

180. Bigos SJ, Boyer OR, Braen GR et al. Acute Low Back Problems in Adults. Clinical Practice Guideline Number 4. AHCPR Publication No. 95-0642. Agency for Health Care Policy and Research, Public Health Service, US Department of Health and Human Services, Rockville, December 1994.

181. Spitzer WO, Leblanc FE, Dupuis M (eds). Quebec Task Force on Spinal Disorders. Scientific approach to the assessment and management of activity-related spinal disorders: A monograph for clinicians. Spine 1987; (suppl) 12:1-59.

182. Bogduk N. International Spinal Injection Society guidelines for the performance of spinal injection procedures. Part 1: Zygapophyseal joint blocks. Clin J Pain 1997; 13:285-302.

183. Gonzalez EG, Materson RS (eds). The Nonsurgical Management of Acute Low Back Pain. Demos Vermane, New York 1997.

184. Bogduk N. Musculoskeletal pain: Toward precision diagnosis. Progress in Pain Research and Management. In Jensen TS, Turner JA, Wiesenfeld-Hallin Z (eds). Proceedings of the 8 th World Congress on Pain. IASP Press, Seattle, 1997, pp 507-525.

185. Slipman CW, Whyte WS, Chow DW et al. Sacroiliac joint syndrome. Pain Physician 2001; 4:143-152.

186. Trief PM, Grant W, Fredrickson B. A prospective study of psychological predictors of lumbar surgery outcome. Spine 2000;25:2616-2621.

187. Pheasant HC. Sources of failures in laminectomies. Orthop Clin North Am 1975; 6:319-329.

188. Rothman RH, Booth R. Failures of spinal fusion. Orthop Clin North Am 1975; 6:299-304.

189. Doxey NCS, Dzioba RB, Mitson GL et al. Predictors of outcome in back surgery candidates. JClin Psychol 1988; 44:622-622.

190. Riley JL, Robinson ME, Geisser ME et al. Relationship between MMPI-2 cluster profiles and surgical outcome in low-back pain patients. J Spinal Disord 1995; 8:213-219.

191. Spengler DM, Ouelette EA, Battie M et al. Elective discectomy for herniation of a lumbar disc. J Bone Joint Surg 1990; 12:230-237.

192. Herron CD, Turner J, Clancy S et al. The differential utility of the MMPI: A predictor of outcome in lumbar laminectomy for disc herniation vs. spinal stenosis. Spine 1986; 11:847-850.

193. Chapman SL, Pemberton JS. Prediction of treatment outcome from clinically derived MMPI clusters in rehabilitation for chronic low back pain. Clin J Pain 1994; 10:267-276.

194. Turk DC, Fernandez E. Personality assessment and the Minnesota Multiphasic Personality Inventory in chronic pain: Underdeveloped and overexposed. Pain 
Forum 1995; 4:104-107.

195. Helmes E, Reddon JR. A perspective on developments in assessing psychopathology: A critical review of the MMPI and MMPI-2. Psych Bull1993; 113:453-71.

196. Kaufmann PG et al. Behavioral medicine in hypertension: Time for new frontiers. Ann Behav Med 1991;
13:3-4.

197. Keller MB, McCullough JP, Klein DN et al. The acute treatment of chronic major depression: A comparison of nefazodone, cognitive behavioral analysis system of psychotherapy, and their combination. NEnglJMed 2000; 342:1462-1470. 